ISSN 1330-9862

original scientific paper

doi: $10.17113 / \mathrm{ftb} \cdot 54.03 .16 .4413$

\title{
Effect of Encapsulation on Antimicrobial Activity of Herbal Extracts with Lysozyme
}

\author{
Petra Matouskova, Ivana Marova*, Jitka Bokrova and Pavla Benesova \\ Brno University of Technology, Faculty of Chemistry, Department of Food Chemistry and Biotechnology \\ and Materials Research Centre, Purkynova 118, CZ-61200 Brno, Czech Republic \\ Received: August 31, 2015 \\ Accepted: March 11, 2016
}

\begin{abstract}
Summary
Resistance of microorganisms to antibiotics has increased. The use of natural components with antimicrobial properties can be of great significance to reduce this problem. The presented work is focused on the study of the effect of encapsulation of selected plant and animal antimicrobial substances (herbs, spices, lysozyme and nisin) on their activity and stability. Antimicrobial components were packaged into liposomes and polysaccharide particles (alginate, chitosan and starch). Antimicrobial activity was tested against two Gram-positive (Bacillus subtilis and Micrococcus luteus) and two Gram-negative (Escherichia coli and Serratia marcescens) bacteria. Encapsulation was successful in all types of polysaccharide particles and liposomes. The prepared particles exhibited very good long-term stability, especially in aqueous conditions. Antimicrobial activity was retained in all types of particles. Liposomes with encapsulated herb and spice extracts exhibited very good inhibitory effect against all tested bacterial strains. Most of herbal extracts had very good antimicrobial effect against the tested Gram-negative bacterial strains, while Gram-positive bacteria were more sensitive to lysozyme particles. Thus, particles with co-encapsulated herbs and lysozyme are more active against different types of bacteria, and more stable and more effective during long-term storage. Particles with encapsulated mixture of selected plant extracts and lysozyme could be used as complex antimicrobial preparation with controlled release in the production of food and food supplements, pharmaceutical and cosmetic industries.
\end{abstract}

Key words: encapsulation, organic particles, liposomes, herbs, lysozyme, antimicrobial effect

\section{Introduction}

The last decade has been characterized by a growing interest in natural antioxidants. Natural herbal sources contain a diverse array of compounds such as phenolic acids, flavonoids, tannins, vitamins and terpenoids that account for their biological properties. Their antioxidant and antimicrobial abilities and health-promoting properties are mainly attributed to phenolic compounds $(1,2)$. Polyphenols are secondary metabolites ubiquitously distributed in all higher plants, where they have important roles as defense against plant pathogens and other unfavourable environmental conditions. Several thousand plant polyphenols are known, encompassing a wide variety of molecules that contain at least one aromatic ring with one or more hydroxyl groups in addition to other substituents. They have antioxidant, anticancer and anti-inflammatory effects (3). The activity of polyphenols from medicinal plants against a wide range of microorganisms has been extensively investigated. The plant polyphenols represent a source of anti-infective agents against antibiotic-resistant pathogens $(3,4)$.

Recent years have witnessed an increase in the interest in plants (mainly plant aqueous extracts) used for wound healing. Skin, the first barrier between body and 
the outer environment, protects the body from the harsh external conditions. Drug application to the skin surface as topical route of administration has high potential in therapy, and allows delivery and controlled release of active substances into internal environments $(5,6)$. Many of the antimicrobials available on the market are transported with difficulties through cell membranes and exhibit low intracellular activity, resulting in reduced intracellular potency. Additional drawback for effective antimicrobial therapy is the fact that increasing number of microorganisms appear to be developing resistance to potent antimicrobials. Thus, many of the currently available broad-spectrum antibiotics are losing their effect. In addition, many antibiotics suffer from poor bioavailability, due to their limited solubility (7).

Resistance to antimicrobial agents has become an increasingly important and pressing global problem (8). The antibacterial activity of phenolic components is being increasingly documented (1-4). Crude extracts from plants with a history of use in folk medicine have been screened in vitro for antibacterial activity (5). Some researchers have reported synergistic effect of naturally occurring flavonoids and other antibacterial agents against resistant strains of bacteria $(8,9)$. Due to the problem of microbial resistance to antibiotics, attention is given to biologically active components isolated from plant species commonly used in herbal medicine, as they can be used as antimicrobial preparations (10-12).

Many studies focus on the development of nanoparticle systems, with dimensions between 1 and $100 \mathrm{~nm}$, for antimicrobial drug delivery (8). Nanoparticles have unique physicochemical properties such as ultrasmall and controllable size, large surface area to mass ratio, high reactivity and functionalizable structure (13). These properties can be applied to facilitate the administration of antimicrobial drugs, thereby overcoming some of the limitations in traditional antimicrobial therapeutics. In recent years, encapsulation of antimicrobial drugs in nanoparticle systems has emerged as an innovative and promising alternative that enhances therapeutic effectiveness and minimizes undesirable side effects of drugs (14). Extensive studies have demonstrated that nanoparticles such as liposomes, polymeric nanoparticles, solid lipid nanoparticles and others can be used for antimicrobial drug delivery and controlled release (15). Encapsulation provides a means to control stability, solubility, and bioavailability, as well as release of bioactive components. Various techniques of encapsulation of natural bioactive components have been proven as an effective method to increase their absorption in vitro and in vivo (16).

Liposomes are currently the most widely studied antimicrobial and clinically established nanoscale systems for drug delivery. They have been extensively studied in pharmaceutical and cosmetic industries (15-17). Their bilayer structure, resembling cell membrane, enables their easy fusing with infectious microorganisms. Their excellent biocompatibility, biodegradability and possibility to manipulate their size and surface properties makes them ideal particles in drug delivery $(17,18)$. Liposomal antimicrobial delivery systems have also several advantages such as improved solubility, bioavailability and efficacy, reduced toxicity, and increased product stability (17). Be- sides their unique benefits, liposomes show some disadvantages such as low stability, low encapsulation efficiency, high cost of manufacturing, degradation by hydrolysis or oxidation, sedimentation, aggregation or fusion during storage (18). Thus, other natural polymers based on polysaccharides have been tested as delivery systems for antimicrobial agents $(19,20)$.

The aims of the present study are to assess and compare the antimicrobial activities of selected herb and spice extracts. Possibilities of encapsulation of these antimicrobial herb and spice extracts alone and in mixture with lysozyme and nisin were tested. Long-term stability of particles and antimicrobial effect of encapsulated compounds was studied under model conditions.

\section{Materials and Methods}

\section{Chemicals}

ABTS (2,2'azinobis-(3-ethylbenzthiazoline-6-sulfonic acid)), alginate sodium salt, calcium chloride, gallic acid, (+)-catechin, Folin-Ciocalteu's reagent, chitosan, cholesterol, soya bean lecithin, lysozyme from chicken egg white, nisin from Lactococcus lactis sp., potassium persulfate, potato starch and Trolox (6-hydroxy-2,5,7,8-tetramethylchroman)-2-carboxylic acid were purchased from Sigma-Aldrich Chemical Co. (St. Louis, MO, USA). All other solvents and reagents used in the analysis were of analytical grade.

\section{Herbal extracts}

The extracts were prepared from wormwood (Artemisia absinthium L.), thyme (Thymus serpyllum L.), coneflower (Echinacea purpurea L.), liquorice (Glycyrrhiza glabra L.), pot marigold (Calendula officinalis L.), sea buckthorn (Hippophae rhamnoides L.) berries, clove (Syzygium aromaticum L.), common nettle (Urtica dioica L.), sage (Salvia officinalis L.), chamomile (Matricaria chamomilla L.), rosemary (Rosmarinus officinalis L.), elderberry (Sambucus nigra L.), lavender (Lavandula angustifolia Mill.), plantago (Plantago lanceolata L.), marjoram (Origanum majorana L.), St. John's wort (Hypericum perforatum L.), ginger (Zingiber officinale Roscoe) and garlic (Allium sativum L.).

Herbs and spices were bought from the local market in Brno, Czech Republic. Three different solvents (water, ethanol and citric acid) were used separately to extract each spice and herb. Water extracts were prepared by adding $10 \mathrm{~g}$ of spice or herb to $100 \mathrm{~mL}$ of hot sterilized distilled water. These were allowed to stand for $15 \mathrm{~min}$ and then filtered through a cheesecloth. The filtrates were kept in sterilized vials. Other extracts were prepared analogously, where the water was replaced with $10 \%$ citric acid and/or $20 \%$ ethanol solution. Total phenolic and flavonoid contents, antioxidant activity and antimicrobial potential of the spice and herb extracts were analysed. Finally, these extracts were used for encapsulation into liposome and polysaccharide particles.

\section{Determination of antioxidant activity using ABTS}

Total antioxidant activity was determined by ABTS radical cation decolourization assay (21). ABTS was dis- 
solved in water to a 7-mM concentration. The ABTS radical cation $\left(\mathrm{ABTS}^{\bullet+}\right)$ was produced by reacting ABTS stock solution with $2.45 \mathrm{mM}$ potassium persulfate and allowing the mixture to stand in the dark at room temperature for 12-16 $\mathrm{h}$ before use. The ABTS ${ }^{\bullet+}$ solution was diluted with ethanol to an absorbance of $0.70 \pm 0.02$ at $734 \mathrm{~nm}$. Then, $1 \mathrm{~mL}$ of diluted $\mathrm{ABTS}^{*+}$ solution was added to $0.010 \mathrm{~mL}$ of antioxidant compound or Trolox standard. The absorbance of the samples was read at $734 \mathrm{~nm}$ using a UV-Vis spectrophotometer (Thermo Spectronic $\operatorname{Helios}^{\mathrm{TM}} \alpha$, Thermo Fisher UK Ltd., Hemel Hempstead, UK) exactly $10 \mathrm{~min}$ after the initial mixing. Antioxidant activity was calculated as a change in the absorbance. Results were expressed in mg of Trolox equivalent (TE) per gram of dry sample.

\section{Total phenolic and total flavonoid contents}

The total phenolic content of the three extracts of each spice and herb was measured using the Folin-Ciocalteu colourimetric method (22). Readings were quantified using a standard curve of gallic acid and the results were expressed in mg of gallic acid equivalent (GAE) per $g$ of dry sample. The total flavonoid content was measured by the aluminium chloride colorimetric method (23). Readings were quantified using a standard curve of catechin and the results were expressed in $\mathrm{mg}$ of catechin equivalent (CE) per $g$ of dry sample. The measurements were performed using UV-Vis spectrophotometer (Thermo Spectronic Helios ${ }^{\mathrm{TM}} \delta$; Thermo Fisher UK Ltd.).

\section{Liposome preparation}

Liposomes can be prepared from many lipid species and by a variety of methods. Phospholipids from soya bean lecithin are widely used in liposomal active component delivery systems due to their safety and wide availability at relatively low cost for upscale production, which makes unpurified soya bean phospholipids a good alternative and attractive choice. The major phospholipids in soya bean lecithin are phosphatidylcholine, phosphatidylethanolamine and phosphatidylinositol (17). In this study, active components were encapsulated into liposome nanoparticles prepared using soya bean lecithin. Three different methods for liposome preparation were tested: ethanol injection, thin film evaporation and ultrasonication. For the formation of liposome, a solution of lecithin of 8 to $45 \mathrm{mg} / \mathrm{mL}$ with the addition of cholesterol in the ratio of lecithin/cholesterol of 9:1 was used. The lipid dispersion was sonicated $(80 \mathrm{~W}, 20 \mathrm{kHz})$ in an ice bath using ultrasonic homogenizer (BANDELIN Electronic $\mathrm{GmbH} \& \mathrm{Co}$. KG, Berlin, Germany) for a few minutes. During the ethanol injection the lecithin solution of $100 \mathrm{mg} / \mathrm{mL}$ was used. Multilamellar vesicles were prepared using the thin film evaporation. In brief, the lipid phase (lecithin $13.5 \mathrm{mg} / \mathrm{mL}$ with the addition of cholesterol in the ratio of lecithin/cholesterol of 8:1) was dissolved in chloroform (with or without the encapsulated lipophilic component), which was then removed under reduced pressure in a rotary evaporator $\left(\mathrm{IKA}^{\circledR}\right.$-Werke $\mathrm{GmbH} \& \mathrm{Co}$. KG, Staufen, Germany), thus obtaining a thin film of dry lipids on the flask wall. The film was then hydrated by adding distilled water (with or without the encapsulated hydrophilic component) under vigorous stirring in order to stimulate the vesicle formation (17).

\section{Preparation of polysaccharide particles}

Alginate, chitosan and starch particles were prepared by the emulsification method based on gelation and cross-linking of polymers $(15,19,20)$. Sodium alginate is a water-soluble polymer that forms a gel in the presence of multivalent cations such as calcium. The preparation of alginate nanoparticles was achieved in aqueous sodium alginate solution (with an encapsulated component) in which gelation was induced by the addition of calcium chloride solution under intensive stirring. This leads to the formation of invisible clusters of calcium alginate gel beads (15). Chitosan particles were prepared in a similar way as the alginate ones. Methods proposed to prepare chitosan nanoparticles are based on the spontaneous formation of complexes between chitosan and polyanions such as tripolyphosphate (19). Starch nanoparticles were formed using simple, fast and easy method of nanoprecipitation in absolute ethanol under controlled conditions (20).

\section{Particle size and stability analysis}

Particle size and size distribution are the key parameters used for the evaluation of the physical stability of nanoparticles. The dynamic light scattering (DLS) is widely used to determine the size and size distribution of small particles suspended in liquid medium. The mean particle size and size distribution indicated as polydispersity index (PDI) are the typical parameters of this technique. A PDI value between 0.1 and 0.25 indicates a narrow size distribution, while a PDI greater than 0.5 shows a broad size distribution (15). Although DLS techniques provide rapid measurement of particle size and size distribution, they do not have the capability of evaluating particle morphology similarly to direct visualization techniques such as microscopy. Laser Doppler electrophoresis is commonly used to measure zeta potential. This technique evaluates electrophoretic mobility of suspended particles in the medium. It is a general rule of thumb that an absolute value of zeta potential above $60 \mathrm{mV}$ yields excellent stability, value of $30 \mathrm{mV}$ generally results in good stability, $20 \mathrm{mV}$ is acceptable short-term stability and less than $5 \mathrm{mV}$ means fast particle aggregation (15).

In this work, particle size distribution, average size of particles and polydispersity index were analysed by colloidal DLS analyzer Zetasizer Nano ZS (Malvern Instruments Ltd., Malvern, UK). Morphology of the prepared particles was observed by light microscope (Labomed Lx 500; Labomed Inc., Los Angeles, CA, USA) and scanning electron microscope (EVO LS 10; Carl Zeiss AG, Oberkochen, Germany), respectively. For other applications the unified particle size $(100 \mathrm{~nm})$ was obtained using membrane extruder (LiposoFast, AVESTIN Europe $\mathrm{GmbH}$, Mannheim, Germany).

\section{Encapsulation efficiency}

Nisin, lysozyme and the above-mentioned herb and spice extracts were used for encapsulation. Encapsulation efficiency was measured spectrophotometrically (UV-Vis 
spectrophotometer, Thermo Spectronic $\operatorname{Helios}^{\mathrm{TM}} \delta$; Thermo Fisher UK Ltd.) and/or by high-performance liquid chromatography with photodiode array (Thermo Fisher Scientific, Waltham, MA, USA). Nisin and lysozyme were separated in Aeris peptide XB-C18 column (Phenomenex Inc., Torrance, CA, USA) using isocratic elution with acetonitrile/water mixture (8:2) and the addition of trifluoroacetic acid $(0.1 \%)$. The content of encapsulated components was measured before and after encapsulation. The percentage of encapsulation efficiency (EE) was then calculated according to the following equation:

$$
\mathrm{EE}=\frac{m(\text { total })-m(\text { free })}{m(\text { total })} \cdot 100
$$

\section{Long-term stability of particles}

Stability of the prepared particles was tested under physiological conditions and in food models. Artificial stomach juice was prepared from $0.25 \mathrm{~g}$ of pepsin dissolved in $100 \mathrm{~mL}$ of distilled water. To this solution 0.84 $\mathrm{mL}$ of $35 \%$ hydrochloric acid was added. Final $\mathrm{pH}$ was adjusted to 0.9. Artificial pancreatic fluid was prepared with $0.25 \mathrm{~g}$ of pancreatin and $1.5 \mathrm{~g}$ of natrium hydrogen carbonate in $100 \mathrm{~mL}$ of water $(\mathrm{pH}=8.9)$. Bile fluid was composed of $0.8 \mathrm{~g}$ of bile acid salts dissolved in $200 \mathrm{~mL}$ of phosphate buffer.

Incubation of particles in a ratio of 1:1 was performed at $37^{\circ} \mathrm{C}$ for $20 \mathrm{~min}$ in stomach fluid and pancreatic juice and for $40 \mathrm{~min}$ in bile fluid. After incubation, the mass fractions of total phenolics and lysozyme released from particles were measured.

Food models of four main types were prepared with the following compositions: $3 \%$ solution of acetic acid was used as a model of acidic food $(\mathrm{pH}<4.5)$, neutral food with $\mathrm{pH}>4.5$ was simulated by distilled water, $10 \%$ ethanol solution was prepared as a model of alcoholic beverages and food containing alcohol, and fatty food was simulated by $25 \%$ emulsion of oil in water. Incubation mixture in a ratio of 1:3 (liposome/food model) was incubated for 1,7 and 30 days at $5{ }^{\circ} \mathrm{C}$. Mass fractions of released phenolics and lysozyme were determined in regular intervals.

\section{Microorganisms and cultivation media}

The antibacterial activities of all extracts and other active components were determined against several bacteria. For preliminary testing of antimicrobial activity, two Gram-positive bacteria (Bacillus subtilis CCM 2794 and Micrococcus luteus CCM 1569) and two Gram-negative bacteria (Escherichia coli CCM 7395 and Serratia marcescens CCM 8587) were used. All bacteria tested in this study were supplied by the Czech Collection of Microorganisms in Brno. Bacterial cultures were grown in commercial Luria-Bertani (LB) medium (Himedia Laboratories Pvt. Ltd., Mumbai, India) for E. coli and in commercial meat peptone medium (Himedia Laboratories Pvt. Ltd.) for M. luteus, B. subtilis and S. marcescens. Temperature for B. subtilis cultivation was $30^{\circ} \mathrm{C}$ and for E. coli, M. luteus and S. marcescens $37^{\circ} \mathrm{C}$. Viability of bacteria was followed by flow cytometry (Apogee Flow Systems, Hemel Hempstead, UK).

\section{Determination of antimicrobial activity}

The antimicrobial properties of extracts from a wide variety of plants have been assessed and reviewed previously $(3,4)$. In this work, two most widely used methods for determining the antimicrobial properties of active components, agar diffusion method and broth dilution method (24), were used.

The antimicrobial activity of extracts was evaluated using a slightly modified agar disc or well diffusion method. A bacterial culture grown for $24 \mathrm{~h}$ (approx. 5.10 CFU per plate) was cultivated on the surface of agar medium in Petri dishes. For disc diffusion test, an aliquot (10 $\mu \mathrm{L}$ ) of herb or spice extract was applied on a sterile paper disc on the agar surface. An additional negative control disc was impregnated with $10 \mu \mathrm{L}$ of sterile distilled water. The plates were inverted and incubated for $24 \mathrm{~h}$ at $30^{\circ} \mathrm{C}$ (for B. subtilis) or $37^{\circ} \mathrm{C}$ (for E. coli, M. luteus and S. marcescens). For well diffusion test, an aliquot (10-80 $\mu \mathrm{L})$ of herb or spice extract was applied directly into the wells with 24-hour bacterial culture grown on Petri dishes. The same volume $(10-80 \mu \mathrm{L})$ of sterile distilled water was plated into wells as negative control. The plates were incubated as described above. Microbial inhibition was determined by measuring the diameter of the clear zone (in $\mathrm{mm}$ ) of growth inhibition around each disc or well. Experiments were repeated three times and the results were expressed as average values. Experiments were done at least twice.

In the broth dilution method, bacteria are inoculated into a liquid growth medium in the presence of different concentrations of an antimicrobial agent. The bacterial cell concentration was determined turbidimetrically using ELISA reader (BioTek Instruments $\mathrm{GmbH}$, Bad Friedrichshall, Germany) and expressed as absorbance at $630 \mathrm{~nm}$ $\left(A_{630 \mathrm{~nm}}\right)$. The results are usually presented as values of minimal inhibitory concentration (MIC) or/and minimal bactericidal concentration (MBC). MIC is defined as the lowest concentration of an antimicrobial that prevents the growth of microorganism after a specific incubation time, while MBC is defined as the lowest concentration of an antimicrobial agent needed to kill $99.9 \%$ of the initial inocula (24).

The microbroth dilution assay was used to determine antimicrobial activity and the MIC of some free and encapsulated samples. A volume of $150 \mu \mathrm{L}$ of $2 \cdot 10^{5} \mathrm{CFU} / \mathrm{mL}$ of bacterial culture was added to sterile 96-well microtiter plates (Thermo Scientific ${ }^{\mathrm{TM}}$, Thermo Fisher Scientific, Inc.) followed by $50 \mu \mathrm{L}$ of the antimicrobial sample. The negative control was prepared by adding $150 \mu \mathrm{L}$ of bacterial culture $\left(2 \cdot 10^{5} \mathrm{CFU} / \mathrm{mL}\right)$ followed by $50 \mu \mathrm{L}$ of the sterile distilled water or prepared particles without encapsulated antimicrobial component. The cell concentration change in each well was determined turbidimetrically. Absorbance of the samples in the individual wells was measured using ELISA reader (BioTek Instruments $\mathrm{GmbH})$ at $630 \mathrm{~nm}$, before and after a 24-hour incubation at $30^{\circ} \mathrm{C}$ (for B. subtilis) or $37^{\circ} \mathrm{C}$ (for E. coli, M. luteus and S. marcescens). The MIC was defined as the concentration of antimicrobial agent that allowed an increase in absorbance less than or equal to 0.05 after $24 \mathrm{~h}$ of incubation. 


\section{Statistical analysis}

All analytical determinations were performed at least in triplicates. Results were expressed as mean value \pm standard deviation. Statistical data analysis was conducted using a Microsoft Excel spreadsheet (Microsoft Corporation, Redmond, WA, USA) and STATISTICA v. 12 software (StatSoft CR, s.r.o., Prague, Czech Republic), and the comparison of average values of each treatment was based on the analysis of variance (one-way ANOVA) according to Tukey's test at significance level of $5 \%(p \leq 0.05)$.

\section{Results and Discussion}

\section{Antioxidant activity and the total phenolic content}

The antioxidant activity of 18 tested herb and spice extracts is given in Table 1 . The antioxidant activity (expressed as TE) was the highest in the clove extract (46.7 $\mathrm{mg} / \mathrm{g}$ ) followed by coneflower $(45.6 \mathrm{mg} / \mathrm{g})$, marjoram $(37.7 \mathrm{mg} / \mathrm{g})$ and sage $(34.8 \mathrm{mg} / \mathrm{g})$ extracts. Extracts of thyme, plantago, St. John's wort, ginger and garlic had similar antioxidant activity (around $30 \mathrm{mg} / \mathrm{g}$ on average). The antioxidant activity was lower in the elderberry extract $(24.0 \mathrm{mg} / \mathrm{g})$. Other tested herb extracts had average antioxidant activity around $10 \mathrm{mg} / \mathrm{g}$. The lowest antioxidant activity was measured in the chamomile extract.

Table 1. Antioxidant activity (AA), total phenolic content (TPC) and total flavonoid content (TFC) of tested aqueous extracts of herbs and spices

\begin{tabular}{|c|c|c|c|}
\hline \multirow{2}{*}{ Plant extract } & $w(\mathrm{AA}$ as $\mathrm{TE})$ & $w(\mathrm{TPC}$ as GAE) & $w(\mathrm{TFC}$ as CE) \\
\hline & $\mathrm{mg} / \mathrm{g}$ & $\mathrm{mg} / \mathrm{g}$ & $\mathrm{mg} / \mathrm{g}$ \\
\hline wormwood & $(10.3 \pm 1.3)^{\mathrm{b}}$ & $(11.2 \pm 0.7)^{c}$ & $(14.3 \pm 0.4)^{\mathrm{e}}$ \\
\hline thyme & $(30.4 \pm 1.3)^{\mathrm{d}}$ & $(31.1 \pm 0.8)^{\mathrm{f}}$ & $(29.0 \pm 0.2)^{\mathrm{g}}$ \\
\hline coneflower & $(45.6 \pm 1.5)^{\mathrm{f}}$ & $(31.1 \pm 0.9)^{\mathrm{f}}$ & $(23.6 \pm 0.2)^{\mathrm{f}}$ \\
\hline liquorice & $(7.8 \pm 0.8)^{\mathrm{ab}}$ & $(8.7 \pm 0.4)^{\mathrm{b}}$ & $(6.1 \pm 0.1)^{c}$ \\
\hline pot marigold & $(9.7 \pm 0.5)^{\mathrm{b}}$ & $(23.0 \pm 0.2)^{\mathrm{e}}$ & $(15.5 \pm 0.9)^{\mathrm{e}}$ \\
\hline sea buckthorn & $(10.3 \pm 0.6)^{b}$ & $(3.3 \pm 0.4)^{\mathrm{ab}}$ & $(1.2 \pm 0.0)^{\mathrm{b}}$ \\
\hline sage & $(34.8 \pm 1.6)^{\mathrm{e}}$ & $(34.3 \pm 0.6)^{\mathrm{f}}$ & $(17.2 \pm 0.5)^{\mathrm{e}}$ \\
\hline rosemary & $(11.9 \pm 0.8)^{\mathrm{b}}$ & $(11.5 \pm 0.5)^{c}$ & $(9.5 \pm 0.9)^{\mathrm{d}}$ \\
\hline common nettle & $(9.5 \pm 0.2)^{\mathrm{b}}$ & $(16.3 \pm 0.6)^{d}$ & $(13.8 \pm 1.8)^{\mathrm{e}}$ \\
\hline clove & $(46.7 \pm 1.5)^{\mathrm{f}}$ & $(60.8 \pm 0.6)^{\mathrm{h}}$ & $(16.2 \pm 0.7)^{\mathrm{e}}$ \\
\hline lavender & $(9.6 \pm 0.5)^{\mathrm{b}}$ & $(19.2 \pm 0.8)^{\mathrm{d}}$ & $(10.8 \pm 0.4)^{\mathrm{d}}$ \\
\hline chamomile & $(3.8 \pm 0.1)^{\mathrm{a}}$ & $(5.7 \pm 0.2)^{\mathrm{b}}$ & $(0.6 \pm 0.0)^{\mathrm{a}}$ \\
\hline elderberry & $(24.0 \pm 1.1)^{c}$ & $(38.8 \pm 1.9)^{\mathrm{fg}}$ & $(32.9 \pm 0.9)^{g}$ \\
\hline plantago & $(27.9 \pm 1.3)^{\mathrm{d}}$ & $(43.0 \pm 1.5)^{g}$ & $(24.7 \pm 0.4)^{\mathrm{f}}$ \\
\hline marjoram & $(37.7 \pm 1.8)^{\mathrm{e}}$ & $(48.7 \pm 1.4)^{\mathrm{gh}}$ & $(31.3 \pm 0.8)^{g}$ \\
\hline St. John's wort & $(30.3 \pm 1.7)^{\mathrm{d}}$ & $(44.1 \pm 0.9)^{g}$ & $(39.3 \pm 0.8)^{\mathrm{h}}$ \\
\hline ginger & $(28.9 \pm 1.1)^{\mathrm{d}}$ & $(1.4 \pm 0.1)^{\mathrm{a}}$ & $(0.2 \pm 0.0)^{a}$ \\
\hline garlic & $(31.2 \pm 1.4)^{\mathrm{d}}$ & $(1.5 \pm 0.1)^{\mathrm{a}}$ & $(0.1 \pm 0.0)^{\mathrm{a}}$ \\
\hline
\end{tabular}

Results are presented as mean value \pm standard deviation. Values with the same letter in the same column are not statistically different $(p>0.05)$. TE $=$ Trolox equivalent, $G A E=$ gallic acid equivalent, $\mathrm{CE}=$ catechin equivalent
The highest total phenolic content expressed as GAE (Table 1) was observed also in clove $(60.8 \mathrm{mg} / \mathrm{g})$, followed by marjoram $(44.7 \mathrm{mg} / \mathrm{g})$, St. John's wort $(44.1 \mathrm{mg} / \mathrm{g})$, plantago $(43.0 \mathrm{mg} / \mathrm{g})$, elderberry $(38.8 \mathrm{mg} / \mathrm{g})$ and sage $(34.3$ $\mathrm{mg} / \mathrm{g})$. Statistical difference in the total phenolic content of plant extracts can be seen. The lowest total phenolic content was found in the extracts of garlic and ginger, although they exhibited excellent antioxidant activity. These results may indicate that the phenolic components are not a sole source of antioxidant activity of herbal extracts. Finally, values of the total flavonoid content in the tested plants are also shown in Table 1. These results, in most cases, reflect the total polyphenol content, except in clove extract. The highest total flavonoid content (expressed as CE) was observed in St. John's wort $(39.3 \mathrm{mg} / \mathrm{g})$, followed by elderberry $(32.9 \mathrm{mg} / \mathrm{g})$, marjoram $(31.3 \mathrm{mg} / \mathrm{g})$, thyme $(29.0 \mathrm{mg} / \mathrm{g})$ and plantago $(24.7 \mathrm{mg} / \mathrm{g})$ extracts. From these results it can be seen that there is a statistically significant dependence between the total phenolic content and the total flavonoid content of plant extracts. No correlation was found between the antioxidant activity and phenolic content.

\section{Encapsulation efficiency of natural extracts}

Three types of plant extracts (aqueous, alcoholic and citric acid) were encapsulated into liposomes. Encapsulation was successful in all types of extracts (Table 2). Generally, phenolic components of herbal extracts were preferably encapsulated as aqueous extracts. Conversely, the worst encapsulation efficiency was determined in citric acid extracts. Thus, type of extraction agent has an important influence on the encapsulation efficiency. Encapsulation efficiency of plant extracts in citric acid was in most samples significantly lower than in other solutions, except for common nettle extract (61.2\%). In alcohol extracts the highest encapsulation efficiency was found in clove extract $(55.3 \%)$, followed by the extracts of liquorice $(54.3 \%)$, rosemary (46.5\%) and marjoram (42.5\%).

The highest encapsulation efficiency in aqueous extracts was found in garlic (93.2\%). Very good encapsulation efficiency (greater than $60 \%$ ) was found also in the aqueous extracts of liquorice $(60.2 \%)$, sage $(69.7 \%)$, lavender $(71.9 \%)$ and chamomile $(77.0 \%)$. The wormwood and clove extracts had the lowest encapsulation efficiency (3.7 and $2.5 \%$, respectively).

Another important factor of encapsulation efficiency is material used for particle preparation. Better results of encapsulation efficiency of plant water extracts were achieved more frequently in liposomes than in polysaccharide particles (Table 3). Some extracts, for example that of ginger, exhibited considerably higher encapsulation efficiency in polysaccharide particles $(81.3 \%$ in chitosan and $68.4 \%$ in alginate) than in liposome (28.9\%).

Higher encapsulation efficiency in polysaccharide particles than in liposomes was also determined in sea buckthorn, plantago, wormwood and clove extracts.

Other antimicrobial compounds encapsulated into particles were enzyme lysozyme $(1-10 \mathrm{mg} / \mathrm{mL})$ and bacterial peptide nisin $(0.03-0.3 \mathrm{mg} / \mathrm{mL})$. Similarly to the analyzed plant extracts, both these substances exhibited antimicrobial activity and they belong to Generally Rec- 
Table 2. Encapsulation efficiency (EE) of different herb and spice extracts in liposomes expressed in percentage of entrapped phenolic components

\begin{tabular}{lccc}
\hline \multirow{2}{*}{ Plant extract } & \multicolumn{3}{c}{ EE/\% } \\
\cline { 2 - 4 } & $\begin{array}{c}\text { aqueous } \\
\text { extract }\end{array}$ & $\begin{array}{c}\text { alcohol } \\
\text { extract }\end{array}$ & $\begin{array}{c}\text { citric acid } \\
\text { extract }\end{array}$ \\
\hline wormwood & $(3.7 \pm 0.1)^{\mathrm{a}}$ & $(25.6 \pm 0.8)^{\mathrm{c}}$ & $(2.8 \pm 0.4)^{\mathrm{a}}$ \\
thyme & $(45.2 \pm 2.0)^{\mathrm{e}}$ & $(33.6 \pm 0.8)^{\mathrm{d}}$ & $(17.2 \pm 0.8)^{\mathrm{d}}$ \\
coneflower & $(26.6 \pm 0.8)^{\mathrm{c}}$ & $(25.5 \pm 0.8)^{\mathrm{c}}$ & $(9.1 \pm 0.8)^{\mathrm{b}}$ \\
liquorice & $(60.2 \pm 4.8)^{\mathrm{g}}$ & $(54.3 \pm 1.2)^{\mathrm{f}}$ & $(18.3 \pm 0.7)^{\mathrm{d}}$ \\
pot marigold & $(37.5 \pm 1.1)^{\mathrm{de}}$ & $(34.4 \pm 0.6)^{\mathrm{d}}$ & $(26.9 \pm 0.9)^{\mathrm{e}}$ \\
sea buckthorn & $(20.5 \pm 1.1)^{\mathrm{b}}$ & $(12.9 \pm 0.5)^{\mathrm{b}}$ & $(13.1 \pm 0.4)^{\mathrm{c}}$ \\
sage & $(69.7 \pm 2.6)^{\mathrm{h}}$ & $(32.0 \pm 0.8)^{\mathrm{d}}$ & $(42.4 \pm 0.9)^{\mathrm{f}}$ \\
rosemary & $(35.3 \pm 0.8)^{\mathrm{d}}$ & $(46.5 \pm 1.8)^{\mathrm{e}}$ & $(32.1 \pm 0.5)^{\mathrm{e}}$ \\
common nettle & $(48.5 \pm 3.3)^{\mathrm{f}}$ & $(33.3 \pm 1.7)^{\mathrm{d}}$ & $(61.2 \pm 3.4)^{\mathrm{h}}$ \\
clove & $(2.5 \pm 0.2)^{\mathrm{a}}$ & $(55.3 \pm 5.7)^{\mathrm{f}}$ & $(51.1 \pm 2.8)^{\mathrm{g}}$ \\
lavender & $(71.9 \pm 5.4)^{\mathrm{h}}$ & $(11.2 \pm 0.8)^{\mathrm{b}}$ & $(31.9 \pm 1.9)^{\mathrm{e}}$ \\
chamomile & $(77.0 \pm 6.8)^{\mathrm{h}}$ & $(4.5 \pm 0.1)^{\mathrm{a}}$ & $(2.0 \pm 0.1)^{\mathrm{a}}$ \\
elderberry & $(51.7 \pm 5.2)^{\mathrm{f}}$ & $(6.8 \pm 0.4)^{\mathrm{a}}$ & $(42.4 \pm 0.9)^{\mathrm{f}}$ \\
plantago & $(27.9 \pm 2.1)^{\mathrm{c}}$ & $(15.4 \pm 0.8)^{\mathrm{b}}$ & $(22.7 \pm 0.8)^{\mathrm{de}}$ \\
marjoram & $(37.7 \pm 0.9)^{\mathrm{de}}$ & $(42.5 \pm 0.9)^{\mathrm{e}}$ & $(33.9 \pm 0.6)^{\mathrm{e}}$ \\
St. John's wort & $(39.5 \pm 0.9)^{\mathrm{e}}$ & $(35.6 \pm 0.8)^{\mathrm{d}}$ & $(28.9 \pm 0.9)^{\mathrm{e}}$ \\
ginger & $(28.9 \pm 1.3)^{\mathrm{c}}$ & $(11.5 \pm 0.4)^{\mathrm{b}}$ & $(8.0 \pm 0.3)^{\mathrm{b}}$ \\
garlic & $(93.2 \pm 8.2)^{\mathrm{i}}$ & $(15.2 \pm 0.4)^{\mathrm{b}}$ & $(9.6 \pm 0.3)^{\mathrm{b}}$ \\
\hline
\end{tabular}

Results are presented as mean value \pm standard deviation.

Values with the same letter in the same column are not statistically different $(p>0.05)$

ognized as Safe (GRAS) compounds that can be used in food and cosmetics. Different concentrations of lecithin $(8-45 \mathrm{mg} / \mathrm{mL})$ and methods of liposome preparation (sonication, thin film evaporation and ethanol injection) were tested for liposome preparation. High encapsulation efficiency of lysozyme (Table 4) was determined in alginate and starch particles (about $90 \%$ ), while in chitosan particles encapsulation efficiency of $21.9 \%$ was achieved. In liposome particles prepared by sonication, high encapsulation efficiency was found in lysozyme.
Table 3. Encapsulation efficiency (EE) of different herb and spice water extracts in liposomes and in polysaccharide particles expressed in percentage of entrapped phenolic components

\begin{tabular}{lccc}
\hline & \multicolumn{3}{c}{ EE/\% } \\
\cline { 2 - 4 } Plant extract & liposome & $\begin{array}{l}\text { alginate } \\
\text { particle }\end{array}$ & $\begin{array}{l}\text { chitosan } \\
\text { particle }\end{array}$ \\
\hline wormwood & $(3.7 \pm 0.2)^{\mathrm{a}}$ & $(28.9 \pm 0.8)^{\mathrm{c}}$ & $(35.5 \pm 2.2)^{\mathrm{d}}$ \\
thyme & $(45.2 \pm 0.9)^{\mathrm{e}}$ & $(36.5 \pm 0.9)^{\mathrm{d}}$ & $(43.8 \pm 2.2)^{\mathrm{e}}$ \\
coneflower & $(26.6 \pm 0.8)^{\mathrm{c}}$ & $(19.0 \pm 0.5)^{\mathrm{b}}$ & $(28.4 \pm 0.8)^{\mathrm{c}}$ \\
liquorice & $(60.2 \pm 2.4)^{\mathrm{g}}$ & $(38.2 \pm 0.8)^{\mathrm{d}}$ & $(47.3 \pm 2.8)^{\mathrm{f}}$ \\
pot marigold & $(37.5 \pm 0.8)^{\mathrm{de}}$ & $(32.0 \pm 0.8)^{\mathrm{c}}$ & $(35.7 \pm 0.9)^{\mathrm{d}}$ \\
sea buckthorn & $(20.5 \pm 0.5)^{\mathrm{b}}$ & $(46.5 \pm 1.4)^{\mathrm{e}}$ & $(39.5 \pm 0.9)^{\mathrm{e}}$ \\
sage & $(69.7 \pm 5.4)^{\mathrm{h}}$ & $(41.9 \pm 1.8)^{\mathrm{e}}$ & $(50.3 \pm 2.9)^{\mathrm{f}}$ \\
rosemary & $(35.3 \pm 3.3)^{\mathrm{d}}$ & $(13.9 \pm 0.5)^{\mathrm{a}}$ & $(8.1 \pm 0.8)^{\mathrm{a}}$ \\
common nettle & $(48.0 \pm 0.8)^{\mathrm{f}}$ & $(18.0 \pm 0.4)^{\mathrm{b}}$ & $(16.0 \pm 0.6)^{\mathrm{b}}$ \\
clove & $(2.5 \pm 0.4)^{\mathrm{a}}$ & $(29.6 \pm 0.4)^{\mathrm{c}}$ & $(42.1 \pm 1.3)^{\mathrm{e}}$ \\
lavender & $(71.9 \pm 4.8)^{\mathrm{h}}$ & $(31.8 \pm 0.8)^{\mathrm{c}}$ & $(23.0 \pm 0.8)^{\mathrm{c}}$ \\
chamomile & $(77.0 \pm 4.4)^{\mathrm{h}}$ & $(22.5 \pm 0.7)^{\mathrm{b}}$ & $(23.9 \pm 0.8)^{\mathrm{c}}$ \\
elderberry & $(51.7 \pm 5.2)^{\mathrm{f}}$ & $(31.5 \pm 0.4)^{\mathrm{c}}$ & $(24.4 \pm 0.8)^{\mathrm{c}}$ \\
plantago & $(27.9 \pm 0.8)^{\mathrm{c}}$ & $(41.6 \pm 1.7)^{\mathrm{e}}$ & $(37.0 \pm 0.6)^{\mathrm{d}}$ \\
marjoram & $(37.7 \pm 0.7)^{\mathrm{de}}$ & $(11.7 \pm 0.1)^{\mathrm{a}}$ & $(17.8 \pm 0.4)^{\mathrm{b}}$ \\
St. John's wort & $(39.5 \pm 1.8)^{\mathrm{e}}$ & $(20.5 \pm 0.4)^{\mathrm{b}}$ & $(36.0 \pm 0.5)^{\mathrm{d}}$ \\
ginger & $(28.9 \pm 0.6)^{\mathrm{c}}$ & $(68.4 \pm 4.4)^{\mathrm{g}}$ & $(81.3 \pm 5.6)^{\mathrm{g}}$ \\
garlic & $(93.0 \pm 8.4)^{\mathrm{i}}$ & $(62.0 \pm 3.3)^{\mathrm{f}}$ & $(44.0 \pm 0.9)^{\mathrm{e}}$ \\
\hline
\end{tabular}

Results are presented as mean value \pm standard deviation.

Values with the same letter in the same column are not statistically different $(p>0.05)$

In further experiments, encapsulation of mixtures of five selected herbal water extracts and lysozyme (0.5-1 $\mathrm{mg} / \mathrm{mL}$ ) was tested. Plant aqueous extracts were chosen according to their phenolic content, antioxidant activity and encapsulation efficiency. The following plant extracts were co-encapsulated with lysozyme in a ratio of 1:1 (by volume): thyme, sage, lavender, elderberry and marjoram. Encapsulation efficiencies of these extracts in liposomes are shown in Fig. 1. Negative influence of co-encapsulation on encapsulation efficiency of individual components

Table 4. Encapsulation (EE) efficiency and characterization of particles with lysozyme and nisin encapsulated in liposomes and polysaccharides

\begin{tabular}{|c|c|c|c|c|c|c|}
\hline \multirow{2}{*}{$\begin{array}{l}\text { Particle material } \\
\text { and technique }\end{array}$} & \multicolumn{2}{|c|}{$\mathrm{EE} / \%$} & \multicolumn{2}{|c|}{$d / \mathrm{nm}$} & \multicolumn{2}{|c|}{$\zeta$-potential/mV } \\
\hline & nisin & lysozyme & nisin & lysozyme & nisin & lysozyme \\
\hline liposome/sonication & $25.6^{\mathrm{d}}$ & $59.5^{\mathrm{b}}$ & $342.5^{4}$ & $280.8^{1}$ & $-53.8^{\mathrm{F}}$ & $-63.5^{\mathrm{G}}$ \\
\hline liposome/TFE & $29.8^{\mathrm{d}}$ & $40.5^{c}$ & $298.7^{2}$ & $305.0^{3}$ & $-62.1^{\mathrm{G}}$ & $-48.3^{\mathrm{E}}$ \\
\hline liposome/EI & $11.9^{\mathrm{f}}$ & $17.2^{\mathrm{ef}}$ & $285.8^{2}$ & $268.3^{1}$ & $-38.5^{\mathrm{D}}$ & $-28.9^{C}$ \\
\hline alginate & $35.2^{\mathrm{cd}}$ & $94.6^{\mathrm{a}}$ & $458.7^{5}$ & $533.8^{6}$ & $-21.3^{\mathrm{B}}$ & $-23.4^{\mathrm{B}}$ \\
\hline chitosan & $21.2^{\mathrm{e}}$ & $21.9^{\mathrm{e}}$ & $289.2^{2}$ & $297.9^{2}$ & $43.6^{\mathrm{DE}}$ & $39.4^{\mathrm{D}}$ \\
\hline starch & $11.8^{\mathrm{f}}$ & $89.5^{\mathrm{a}}$ & $309.1^{3}$ & $341.8^{4}$ & $-13.4^{\mathrm{A}}$ & $-12.4^{\mathrm{A}}$ \\
\hline
\end{tabular}

Three different parameters were used for characterization of organic particles prepared from different material. Statistical analysis was done for each of these parameters individually. Lowercase letter in superscript denotes statistical evaluation of encapsulation efficiency, capital letter stands for statistical evaluation of zeta potential and number represents statistical evaluation of particle diameter. Values with the same letter or number in superscript are not statistically different $(\mathrm{p}>0.05)$. Methods for liposome preparation: thin film evaporation (TFE) and ethanol injection (EI); $d=$ diameter of particle 


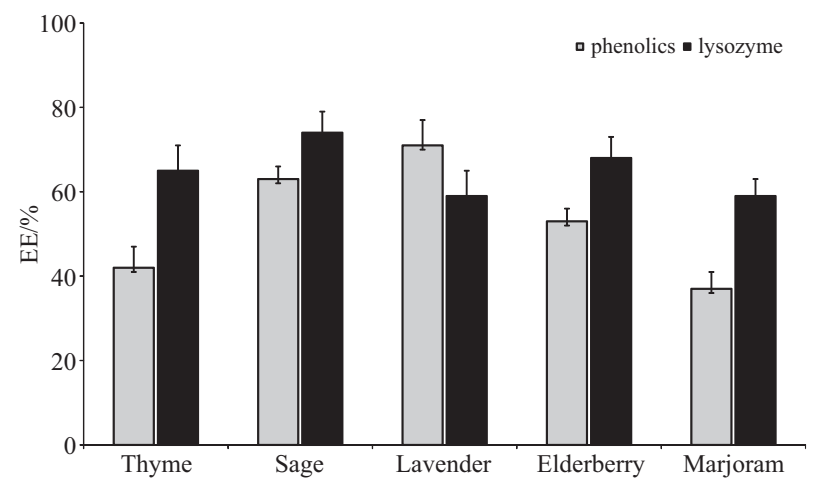

Fig. 1. Encapsulation efficiency (EE) of liposome containing a mixture of plant extracts and lysozyme evaluated as a percentage of entrapped phenolics and lysozyme

was not found; moreover, some increase of encapsulation efficiency was observed when compared with individual extracts and lysozyme.

\section{Stability and size of polysaccharide particles}

The average size of polysaccharide particles containing nisin or lysozyme was larger than liposomes containing nisin or lysozyme (Table 4). Polydispersity index of polysaccharide particles was in a range from 0.2 to 0.6 (data not shown). Because of substantially higher encapsulation efficiency of lysozyme than nisin in all types of particles, further experiments of co-encapsulation of antimicrobial herbal extracts and peptide were done with lysozyme only.

Generally, it can be said that most stable particles containing lysozyme and nisin (Table 4) were prepared by sonication and then by evaporation on a thin layer, regardless of the encapsulated active component. Zeta potential of prepared liposomes was in almost all cases in the range from -30 to $-60 \mathrm{mV}$. Zeta potential of prepared polysaccharide particles was good, too. Chitosan particles were the most stable, while starch particles $(-12.4 \mathrm{mV})$ were determined as the least stable (Table 4).

Size of the prepared liposomes containing plant extracts (Table 5) was on average $180 \mathrm{~nm}(121.0-358.3 \mathrm{~nm}$ ) and a polydispersity index value was not greater than 0.25 , except for particles with garlic extract (data not shown). Zeta potential of these liposomes was in almost all cases in the range of -30 to $-60 \mathrm{mV}$, which means that particles (except thyme) were stable. Statistically significantly higher values of zeta potential were found in liposomes with encapsulated plantago, lavender, clove, sea buckthorn and St. John's wort extracts (Table 5). Particles containing ginger, thyme and wormwood extracts were less stable than empty liposome capsule under the same conditions. Zeta potential was also used for evaluation of colloid stability of liposomes with co-encapsulated lysozyme and selected plant extracts and it showed that particles were stable below $-30 \mathrm{mV}$ (Fig. 2).

\section{Long-term stability of prepared particles}

Studies of the stability of liposome particles with encapsulated plant extracts, antimicrobial peptides and their mixtures were performed in different model food and physiological conditions as described in Materials and Methods.
Table 5. Average value of diameter $(d)$ and zeta potential of liposomes with encapsulated plant antimicrobial component, based on DLS measurement

\begin{tabular}{llc}
\hline Plant material & $d / \mathrm{nm}$ & $\zeta$-potential/mV \\
\hline wormwood & $215.9^{\mathrm{d}}$ & $-31.4^{\mathrm{c}}$ \\
thyme & $219.1^{\mathrm{d}}$ & $-28.3^{\mathrm{d}}$ \\
coneflower & $167.0^{\mathrm{b}}$ & $-42.5^{\mathrm{b}}$ \\
liquorice & $185.6^{\mathrm{c}}$ & $-37.7^{\mathrm{c}}$ \\
pot marigold & $204.3^{\mathrm{d}}$ & $-47.4^{\mathrm{a}}$ \\
sea buckthorn & $162.3^{\mathrm{b}}$ & $-47.0^{\mathrm{a}}$ \\
sage & $188.0^{\mathrm{c}}$ & $-38.0^{\mathrm{bc}}$ \\
rosemary & $186.0^{\mathrm{c}}$ & $-37.4^{\mathrm{c}}$ \\
common nettle & $192.0^{\mathrm{cd}}$ & $-36.2^{\mathrm{c}}$ \\
clove & $121.0^{\mathrm{a}}$ & $-44.9^{\mathrm{a}}$ \\
lavender & $183.0^{\mathrm{c}}$ & $-42.5^{\mathrm{b}}$ \\
chamomile & $202.0^{\mathrm{d}}$ & $-35.1^{\mathrm{c}}$ \\
elderberry & $204.0^{\mathrm{d}}$ & $-38.2^{\mathrm{bc}}$ \\
plantago & $187.1^{\mathrm{c}}$ & $-42.2^{\mathrm{b}}$ \\
marjoram & $199.5^{\mathrm{d}}$ & $-39.1^{\mathrm{bc}}$ \\
St. John's wort & $211.0^{\mathrm{d}}$ & $-45.7^{\mathrm{a}}$ \\
ginger & $175.9^{\mathrm{bc}}$ & $-31.0^{\mathrm{c}}$ \\
garlic & $358.3^{\mathrm{d}}$ & $-47.3^{\mathrm{b}}$ \\
\hline empty capsule & $166.9^{\mathrm{b}}$ & $-33.4^{\mathrm{c}}$ \\
\hline
\end{tabular}

Relative standard deviation did not exceed $5 \%$; values with the same letter in the same column are not statistically different ( $\mathrm{p}>0.05)$; DLS=dynamic light scattering

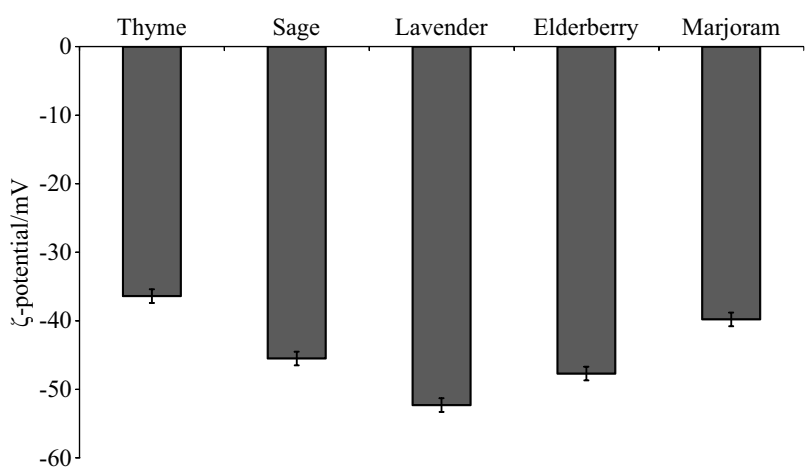

Fig. 2. Colloid stability of liposome with co-encapsulated plant extracts and lysozyme measured as zeta potential

The effect of temperature on the long-term stability of particles containing nisin or lysozyme was analyzed (Table 6). The mass fraction of released antimicrobial components was the highest in acidic medium. Fatty medium also led to greater release of active components. Conversely, particles were stable in aqueous medium. In the ethanol medium the release of active substances depended mainly on the temperature. At $28^{\circ} \mathrm{C}$, significant mass fraction of lysozyme was released, while at $5{ }^{\circ} \mathrm{C}$ minimum mass fraction of lysozyme was found outside the particles (Table 6). Thus, the results imply that storage at higher temperatures leads to significant release of active ingredients.

The long-term stability of particles containing an antimicrobial herb and spice extract was analyzed as well (Table 7). The particles were added to the aqueous model 
Table 6. Effect of temperature on long-term stability of prepared liposomes

\begin{tabular}{|c|c|c|c|c|c|c|c|c|}
\hline \multirow{4}{*}{ Material } & \multicolumn{8}{|c|}{ Temperature $/{ }^{\circ} \mathrm{C}$} \\
\hline & \multicolumn{2}{|c|}{ Acidic food } & \multicolumn{2}{|c|}{ Food containing water } & \multicolumn{2}{|c|}{ Food containing ethanol } & \multicolumn{2}{|c|}{ Fatty food } \\
\hline & 5 & 28 & 5 & 28 & 5 & 28 & 5 & 28 \\
\hline & \multicolumn{8}{|c|}{$w$ (released protein) $/ \%$} \\
\hline nisin & $29.3^{\mathrm{e}}$ & $50.0^{\mathrm{h}}$ & $2.0^{\mathrm{a}}$ & $9.6^{\mathrm{b}}$ & $4.1^{\mathrm{a}}$ & $19.8^{\mathrm{c}}$ & $29.5^{\mathrm{e}}$ & 58.8 \\
\hline lysozyme & $63.7^{\mathrm{i}}$ & $35.8^{f}$ & $8.5^{\mathrm{b}}$ & $1.2^{\mathrm{a}}$ & $25.4^{\mathrm{d}}$ & $3.0^{\mathrm{a}}$ & $84.0^{\mathrm{j}}$ & $40.0^{8}$ \\
\hline
\end{tabular}

Mean values with different letters in superscript are statistically different $(\mathrm{p}<0.05)$

Table 7. Effect of time on long-term stability of prepared liposomes

\begin{tabular}{|c|c|c|c|c|c|c|c|c|}
\hline \multirow{4}{*}{ Plant material } & \multicolumn{8}{|c|}{ t/day } \\
\hline & \multicolumn{2}{|c|}{ Acidic food } & \multicolumn{2}{|c|}{ Food containing water } & \multicolumn{2}{|c|}{ Food containing ethanol } & \multicolumn{2}{|c|}{ Fatty food } \\
\hline & 7 & 30 & 7 & 30 & 7 & 30 & 7 & 30 \\
\hline & \multicolumn{8}{|c|}{$w($ released phenolics $) / \%$} \\
\hline wormwood & $17.9^{f}$ & $68.2^{g}$ & $12.8^{\mathrm{c}}$ & $47.7^{f}$ & $18.6^{\mathrm{e}}$ & $65.5^{\mathrm{g}}$ & $25.3^{\mathrm{d}}$ & $69.9^{\mathrm{fg}}$ \\
\hline thyme & $9.9^{\text {cd }}$ & $42.2^{\mathrm{d}}$ & $7.2^{\mathrm{b}}$ & $20.5^{\mathrm{d}}$ & $15.2^{\mathrm{de}}$ & $36.9^{d}$ & $7.0^{\mathrm{b}}$ & $48.3^{\mathrm{d}}$ \\
\hline coneflower & $11.0^{\mathrm{d}}$ & $61.9^{f}$ & $3.4^{\mathrm{ab}}$ & $21.6^{\mathrm{d}}$ & $11.1^{\mathrm{d}}$ & $51.2^{\mathrm{f}}$ & $13.2^{\mathrm{c}}$ & $31.2^{\mathrm{c}}$ \\
\hline liquorice & $10.5^{\mathrm{d}}$ & $53.3^{e}$ & $15.9^{c}$ & $39.8^{\mathrm{e}}$ & $36.2^{\mathrm{f}}$ & $67.5^{\mathrm{g}}$ & $16.3^{c}$ & $54.4^{\mathrm{e}}$ \\
\hline pot marigold & $12.4^{\mathrm{e}}$ & $29.1^{c}$ & $48.1^{\mathrm{f}}$ & $80.3^{g}$ & $23.1^{\text {ef }}$ & $49.1^{\text {ef }}$ & $13.1^{c}$ & $68.0^{\mathrm{f}}$ \\
\hline sea buckthorn & $6.2^{\mathrm{b}}$ & $32.1^{\mathrm{c}}$ & $21.4^{\mathrm{d}}$ & $50.0^{f}$ & $20.6^{\mathrm{e}}$ & $44.4^{\mathrm{e}}$ & $15.5^{c}$ & $35.0^{c}$ \\
\hline sage & $8.3^{c}$ & $55.3^{e}$ & $6.4^{\mathrm{b}}$ & $12.1^{\mathrm{b}}$ & $12.5^{\mathrm{d}}$ & $41.3^{\mathrm{e}}$ & $37.1^{\mathrm{e}}$ & $78.1^{g}$ \\
\hline rosemary & n.d. & $5.4^{\mathrm{a}}$ & $7.2^{\mathrm{b}}$ & $12.9^{\mathrm{b}}$ & n.d. & $24.6^{c}$ & n.d. & $11.8^{\mathrm{a}}$ \\
\hline common nettle & $28.6^{\mathrm{g}}$ & $85.9^{\mathrm{h}}$ & $9.5^{\mathrm{bc}}$ & $25.6^{\mathrm{de}}$ & $35.1^{f}$ & $72.2^{\mathrm{h}}$ & $35.5^{\mathrm{e}}$ & $64.5^{\mathrm{f}}$ \\
\hline clove & $1.2^{\mathrm{a}}$ & $16.8^{\mathrm{b}}$ & $6.9^{\mathrm{b}}$ & $24.8^{\mathrm{de}}$ & $3.8^{\mathrm{a}}$ & $5.4^{\mathrm{a}}$ & $5.1^{\mathrm{a}}$ & $39.1^{c d}$ \\
\hline lavender & $4.5^{\mathrm{b}}$ & $19.5^{\mathrm{b}}$ & $5.5^{\mathrm{b}}$ & $38.1^{\mathrm{e}}$ & $6.3^{\mathrm{b}}$ & $26.9^{c}$ & $11.1^{\mathrm{bc}}$ & $34.0^{c}$ \\
\hline chamomile & $22.7^{\mathrm{fg}}$ & $69.1^{g}$ & $44.1^{\mathrm{f}}$ & $100.0^{\mathrm{i}}$ & $6.9^{b c}$ & $15.9^{\mathrm{b}}$ & $27.9^{d}$ & $65.4^{\mathrm{f}}$ \\
\hline elderberry & $0.8^{\mathrm{a}}$ & $2.3^{\mathrm{a}}$ & $2.4^{\mathrm{a}}$ & $15.0^{c}$ & $8.0^{c}$ & $12.9^{\mathrm{b}}$ & $28.5^{\mathrm{d}}$ & $52.6^{\mathrm{e}}$ \\
\hline plantago & $10.5^{\mathrm{d}}$ & $53.3^{e}$ & $3.1^{\mathrm{ab}}$ & $5.5^{\mathrm{a}}$ & $11.2^{\mathrm{d}}$ & $44.8^{\mathrm{e}}$ & $8.6^{\mathrm{b}}$ & $44.0^{\mathrm{d}}$ \\
\hline marjoram & $5.7^{\mathrm{b}}$ & $45.2^{\mathrm{d}}$ & $0.2^{\mathrm{a}}$ & $11.2^{\mathrm{b}}$ & $5.5^{\mathrm{b}}$ & $31.7^{\mathrm{cd}}$ & $3.8^{\mathrm{a}}$ & $31.4^{c}$ \\
\hline St. John's wort & $13.1^{\mathrm{e}}$ & $58.8^{\mathrm{ef}}$ & $74.7^{\mathrm{g}}$ & $90.0^{\mathrm{h}}$ & $10.2^{\mathrm{d}}$ & $54.2^{\mathrm{f}}$ & $19.7^{\text {cd }}$ & $68.0^{\mathrm{f}}$ \\
\hline ginger & $8.4^{\mathrm{c}}$ & $26.8^{\mathrm{bc}}$ & $14.5^{\mathrm{c}}$ & $100.0^{\mathrm{i}}$ & $5.5^{\mathrm{b}}$ & $35.0^{d}$ & $13.2^{c}$ & $22.4^{\mathrm{b}}$ \\
\hline garlic & $11.8^{\mathrm{d}}$ & $65.4^{\mathrm{f}}$ & $29.0^{\mathrm{e}}$ & $41.6^{\mathrm{e}}$ & $19.8^{\mathrm{e}}$ & $44.6^{\mathrm{e}}$ & $8.9^{\mathrm{b}}$ & $39.9^{\mathrm{cd}}$ \\
\hline
\end{tabular}

Values with the same letter in the same column are not statistically different $(p>0.05)$; n.d.=not detected

solution and stored at $5{ }^{\circ} \mathrm{C}$. At fixed intervals, samples were taken to determine the mass fraction of released components. Very good stability of most herbal particles was observed during storage in an aqueous medium, without the significant release of phenolic components. Only in the case of liposome with St. John's wort extract a significant release of the encapsulated phenolic components (74.7\%) was detected after 7 days of storage (Table 7). Slow release of polyphenols from the particles was also observed after 7 days of storage in liposomes with garlic $(29.0 \%)$, chamomile $(44.1 \%)$ and pot marigold $(48.1 \%)$ extracts. In liposomes containing extracts of wormwood, liquorice, pot marigold, sea buckthorn, lavender and garlic, the increase of phenolics was recorded after 30 days of storage. Liposomes containing St. John's wort, chamomile and ginger extracts were less stable after 30 days of storage in water medium (Table 7). Conversely, long-term stability of liposome containing a plant extract was significantly higher in particles with rosemary, marjoram, clove and thyme in most environments (Table 7). However, variability of data in dependence on the combination of active component and environment was relatively high.

These findings were confirmed during long-term storage experiments with mixtures of plant extracts and lysozyme in liposomes (Table 8). During one week of storage, the highest stability of encapsulated phenolics was found in water medium. Particles stored in fatty medium were less stable. Water medium was confirmed as the most suitable for long-term storage of particles with mixed antimicrobial compounds. Stabilization effect of herbal extracts on lysozyme and decreased lysozyme release was observed mainly in particles with sage and thyme stored in water (Table 8).

The stability of particles containing a mixture of an antimicrobial herb and spice extracts was also tested in 
Table 8. Long-term stability of co-encapsulated plant extracts and lysozyme in different food models

\begin{tabular}{|c|c|c|c|c|c|c|c|c|c|c|c|c|c|c|c|c|}
\hline \multirow{5}{*}{ Material } & \multicolumn{16}{|c|}{$t$ (incubation)/day } \\
\hline & \multicolumn{4}{|c|}{ Acidic food } & \multicolumn{4}{|c|}{ Food containing water } & \multicolumn{4}{|c|}{ Food containing ethanol } & \multicolumn{4}{|c|}{ Fatty food } \\
\hline & \multicolumn{2}{|c|}{ Phenolics } & \multicolumn{2}{|c|}{ Lysozyme } & \multicolumn{2}{|c|}{ Phenolics } & \multicolumn{2}{|c|}{ Lysozyme } & \multicolumn{2}{|c|}{ Phenolics } & \multicolumn{2}{|c|}{ Lysozyme } & \multicolumn{2}{|c|}{ Phenolics } & \multicolumn{2}{|c|}{ Lysozyme } \\
\hline & 7 & 30 & 7 & 30 & 7 & 30 & 7 & 30 & 7 & 30 & 7 & 30 & 7 & 30 & 7 & 30 \\
\hline & \multicolumn{16}{|c|}{$w($ released $) / \%$} \\
\hline thyme & $9.9^{\mathrm{bc}}$ & $42.2^{\mathrm{ef}}$ & $45.0^{f}$ & $63.7^{\mathrm{h}}$ & $7.6^{\mathrm{b}}$ & $20.5^{\mathrm{cd}}$ & $3.2^{\mathrm{a}}$ & $35.6^{\mathrm{e}}$ & $15.2^{\mathrm{c}}$ & $36.9^{\mathrm{e}}$ & $9.9^{\mathrm{bc}}$ & $19.8^{\mathrm{cd}}$ & $7.0^{\mathrm{b}}$ & $48.3^{\mathrm{f}}$ & $9.0^{\mathrm{b}}$ & $58.8^{\mathrm{gh}}$ \\
\hline sage & $8.3^{\mathrm{b}}$ & $55.3^{g}$ & $19.0^{\text {cd }}$ & $58.5^{\mathrm{gh}}$ & $11.3^{\mathrm{bc}}$ & $12.1^{\mathrm{c}}$ & $1.1^{\mathrm{a}}$ & $11.5^{\mathrm{c}}$ & $12.5^{\mathrm{c}}$ & $41.3^{\mathrm{ef}}$ & $6.3^{\mathrm{b}}$ & $22.9^{\mathrm{d}}$ & $37.1^{\mathrm{e}}$ & $78.1^{\mathrm{i}}$ & $4.8^{\mathrm{ab}}$ & $55.5^{\mathrm{g}}$ \\
\hline lavender & $4.5^{\mathrm{ab}}$ & $19.5^{\mathrm{cd}}$ & $22.1^{\mathrm{d}}$ & $77.6^{\mathrm{i}}$ & $19.3^{\text {cd }}$ & $38.4^{\mathrm{e}}$ & $5.4^{\mathrm{b}}$ & $44.2^{\mathrm{f}}$ & $6.3^{\mathrm{b}}$ & $26.9^{d}$ & $13.0^{c}$ & $25.4^{\mathrm{d}}$ & $11.1^{\mathrm{bc}}$ & $34^{\mathrm{e}}$ & $52.3^{g}$ & $84.0^{\mathrm{i}}$ \\
\hline elderberry & $0.8^{\mathrm{a}}$ & $2.4^{\mathrm{a}}$ & $25.2^{\mathrm{d}}$ & $80.6^{\mathrm{i}}$ & $15.0^{c}$ & $15^{c}$ & $3.9^{\mathrm{ab}}$ & $58.8^{\mathrm{gh}}$ & $8.0^{\mathrm{b}}$ & $12.9^{c}$ & $18.9^{\mathrm{cd}}$ & $35.8^{\mathrm{e}}$ & $28.5^{\mathrm{de}}$ & $52.6^{\mathrm{g}}$ & $28.6^{\mathrm{de}}$ & $97.8^{j}$ \\
\hline majoram & $5.7^{\mathrm{b}}$ & $45.2^{f}$ & $38.2^{\mathrm{e}}$ & $82.5^{\mathrm{i}}$ & $12.5^{c}$ & $11.2^{\mathrm{bc}}$ & $2.8^{\mathrm{a}}$ & $39.4^{\mathrm{e}}$ & $5.5^{\mathrm{b}}$ & $31.7^{\mathrm{e}}$ & $19.9^{\mathrm{cd}}$ & $46.6^{\mathrm{f}}$ & $3.8^{\mathrm{a}}$ & $31.4^{\mathrm{e}}$ & $44.7^{\mathrm{f}}$ & $68.1^{\mathrm{h}}$ \\
\hline lysozyme & n.d. & n.d. & $43.4^{\mathrm{ef}}$ & $103.7^{j}$ & n.d. & n.d. & $12.5^{c}$ & $71.6^{\mathrm{i}}$ & n.d. & n.d. & $35.2^{\mathrm{e}}$ & $62.5^{\mathrm{h}}$ & n.d. & n.d. & $64.7^{\mathrm{h}}$ & $71.8^{\mathrm{i}}$ \\
\hline
\end{tabular}

Mean values with different letters in superscript are statistically different $(\mathrm{p}<0.05) ;$ n.d. $=$ not detected

physiological fluid models, i.e. artificial stomach, bile and pancreatic juices (Fig. 3). The particles were added to the fluids and incubated as described in Materials and Methods. After incubation, samples were taken to determine the mass fraction of released phenolics and lysozyme. While most of phenolic compounds are released from liposomes mainly in artificial pancreatic and bile juices, lysozyme was released intensively also in acidic stomach juice. It can be concluded that co-encapsulation led to better stability of the active compound in the particles and to the better control of its release during digestive processes.
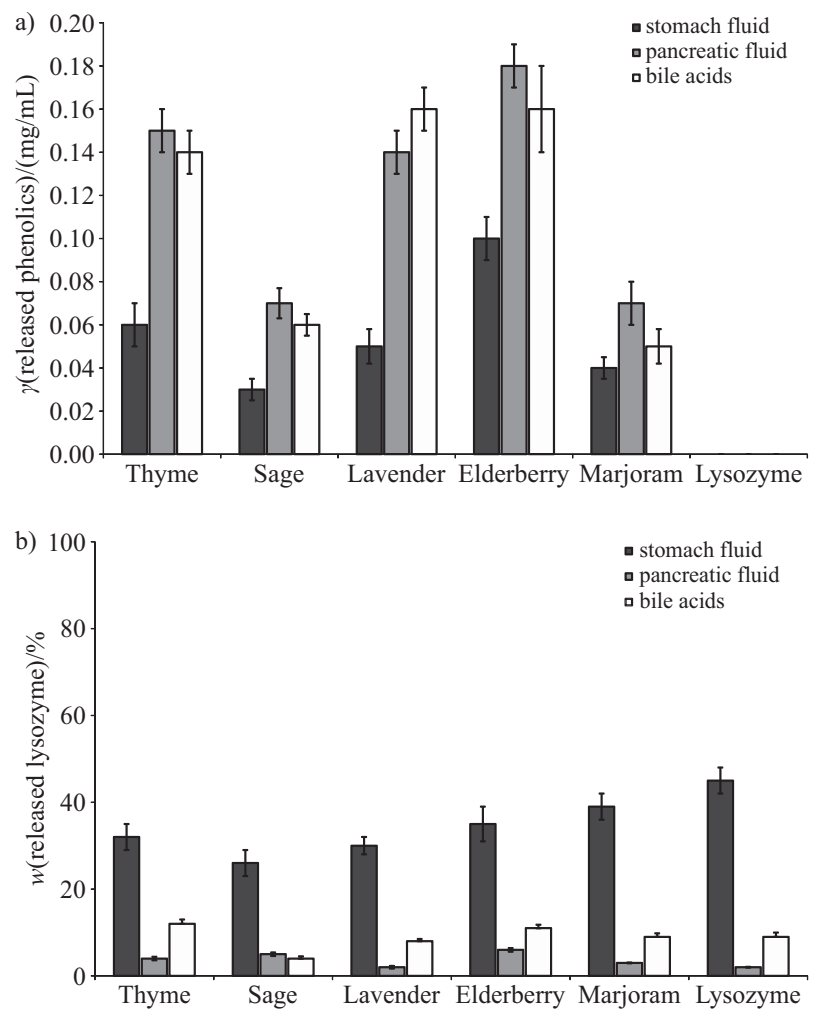

Fig. 3. Long-term stability of co-encapsulated plant extracts and lysozyme in liposomes incubated in different physiological fluid models: a) released phenolics from liposomes with co-encapsulated plant extracts and lysozyme, b) released lysozyme from particles with mixture of plant extract and lysozyme

\section{Antimicrobial activity of herb and spice extracts}

In the present study, the antimicrobial activity of pure herb and spice extracts was determined before and after encapsulation into liposome or polysaccharide particles. Firstly, antimicrobial properties of the plant extracts alone were tested. Significant variations in the antibacterial activity of each tested spice or herb sample were observed among water, ethanol and acid extracts (Table 9). Water extracts showed a significantly higher overall inhibition against all bacterial strains tested than the other extracts. Thus, water extracts were used for encapsulation of plant antimicrobial agents. Antimicrobial activity was followed after 24-hour incubation with tested strain as MIC value as described in Materials and Methods. Results were expressed as $A_{630 \mathrm{~nm}}$ of bacterial culture (turbidity decrease) after incubation with plant extract in free and/or encapsulated form for $24 \mathrm{~h}$. Antimicrobial activity against Bacillus subtilis, Micrococcus luteus, Serratia marcescens and Escherichia coli is shown in Table 9.

All tested pure herbal extracts showed at least a partial antimicrobial activity against all tested strains (Table 9). Interestingly, some of the herbal extracts exhibited relatively good antimicrobial effect against tested Gram-negative strains, mainly E. coli (clove, sea buckthorn, coneflower, wormwood, thyme, liquorice, pot marigold and chamomile). Antimicrobial effect against the Gram-negative strains was observed in all tested extracts except rosemary, ginger and elderberry. In the clove extract almost $100 \%$ inhibitory effect was measured during 24 h. S. marcescens was less sensitive to the antimicrobial effect of plant extracts than E. coli. Inhibitory effect was found in extracts of sea buckthorn, pot marigold, common nettle, clove, coneflower, plantago, marjoram and ginger.

Lysozyme and extracts of clove, coneflower, liquorice, pot marigold, common nettle and plantago exhibited very high inhibitory activity against Gram-positive strain B. subtilis (Table 9). M. luteus was less sensitive, with extracts of sea buckthorn, rosemary, sage, clove, coneflower, chamomile, wormwood and thyme having the highest antimicrobial effect. In some extracts a highly positive relationship between antioxidant activity, antibacterial activity and total phenolic content was confirmed (Tables 1 and 9). Extracts with the highest antioxidant effect like 
Table 9. Antimicrobial activity determined by turbidimetric analysis of water extracts of herbs and spices with and without encapsulation in different types of particles, expressed as absorbance $(A)$ at $630 \mathrm{~nm}$

\begin{tabular}{|c|c|c|c|c|c|c|c|c|c|c|c|c|c|c|c|c|}
\hline \multirow{3}{*}{ Plant material } & \multicolumn{4}{|c|}{ Bacillus subtilis } & \multicolumn{4}{|c|}{ Micrococcus luteus } & \multicolumn{4}{|c|}{ Serratia marcescens } & \multicolumn{4}{|c|}{ Escherichia coli } \\
\hline & PE & $\mathrm{L}$ & $\mathrm{A}$ & $\mathrm{CH}$ & PE & $\mathrm{L}$ & $\mathrm{A}$ & $\mathrm{CH}$ & PE & $\mathrm{L}$ & A & $\mathrm{CH}$ & PE & $\mathrm{L}$ & $\mathrm{A}$ & $\mathrm{CH}$ \\
\hline & \multicolumn{16}{|c|}{$A_{630 \mathrm{~nm}}$} \\
\hline wormwood & $0.78^{\mathrm{i}}$ & $0.51^{\mathrm{f}}$ & $0.59^{\mathrm{g}}$ & $0.33^{\mathrm{d}}$ & $0.52^{\mathrm{f}}$ & $0.51^{\mathrm{f}}$ & $0.49^{f}$ & & 1.02 & $0.00^{\mathrm{a}}$ & $0.12^{\mathrm{b}}$ & $0.02^{\mathrm{a}}$ & $0.28^{\mathrm{d}}$ & $0.26^{\mathrm{cd}}$ & $0.42^{\mathrm{e}}$ & $0.11^{\mathrm{b}}$ \\
\hline thyme & $0.69^{\mathrm{h}}$ & $0.52^{\mathrm{f}}$ & $0.69^{\mathrm{h}}$ & $0.39^{\mathrm{e}}$ & $0.51^{\mathrm{f}}$ & $0.49^{f}$ & $0.53^{f}$ & $0.33^{\mathrm{d}}$ & 0.90 & $0.21^{\mathrm{c}}$ & $0.33^{d}$ & $0.14^{\mathrm{b}}$ & $0.30^{\mathrm{d}}$ & $0.44^{\mathrm{e}}$ & $0.64^{\mathrm{g}}$ & $0.29^{\mathrm{d}}$ \\
\hline coneflower & $0.24^{\mathrm{c}}$ & $0.22^{\mathrm{c}}$ & $0.34^{\mathrm{d}}$ & $0.04^{\mathrm{a}}$ & $0.46^{\mathrm{ef}}$ & $0.33^{\mathrm{d}}$ & $0.43^{\mathrm{e}}$ & $0.11^{\mathrm{b}}$ & $0.77^{\mathrm{hi}}$ & $0.00^{\mathrm{a}}$ & $0.31^{\mathrm{d}}$ & $0.30^{\mathrm{d}}$ & $0.26^{\mathrm{cd}}$ & $0.47^{\mathrm{ef}}$ & $0.62^{\mathrm{g}}$ & $0.45^{\mathrm{ef}}$ \\
\hline iquorice & $0.43^{\mathrm{e}}$ & $0.28^{\mathrm{d}}$ & $0.38^{\mathrm{e}}$ & $0.11^{\mathrm{b}}$ & $0.54^{\mathrm{f}}$ & $0.39^{\mathrm{e}}$ & $0.29^{d}$ & 0.10 & 0.93 & $0.45^{\mathrm{ef}}$ & $0.56^{\mathrm{fg}}$ & $0.10^{\mathrm{b}}$ & $0.31^{\mathrm{d}}$ & $0.13^{\mathrm{b}}$ & $0.32^{\mathrm{d}}$ & $0.10^{\mathrm{b}}$ \\
\hline ot marigold & $0.44^{\mathrm{e}}$ & $0.13^{\mathrm{b}}$ & $0.29^{\mathrm{d}}$ & $0.10^{\mathrm{b}}$ & $0.56^{\mathrm{fg}}$ & $0.20^{c}$ & $0.31^{\mathrm{d}}$ & $0.19^{c}$ & $0.68^{\mathrm{h}}$ & $0.20^{c}$ & $0.45^{\mathrm{ef}}$ & $0.34^{\mathrm{d}}$ & $0.44^{\mathrm{e}}$ & $0.11^{\mathrm{b}}$ & $0.51^{\mathrm{f}}$ & $0.21^{c}$ \\
\hline sea buckthorn & 0.97 & $0.11^{\mathrm{b}}$ & $0.52^{\mathrm{f}}$ & $0.10^{\mathrm{b}}$ & $0.05^{\mathrm{a}}$ & $0.02^{\mathrm{a}}$ & $0.52^{\mathrm{f}}$ & $0.02^{\mathrm{a}}$ & $0.66^{\mathrm{gh}}$ & $0.28^{\mathrm{d}}$ & $0.65^{\mathrm{g}}$ & $0.15^{\mathrm{b}}$ & $0.07^{\mathrm{b}}$ & $0.11^{\mathrm{b}}$ & $0.69^{\mathrm{h}}$ & $0.13^{\mathrm{b}}$ \\
\hline sage & $0.65^{\mathrm{g}}$ & $0.03^{\mathrm{a}}$ & $0.28^{\mathrm{d}}$ & $0.06^{\mathrm{ab}}$ & $0.14^{\mathrm{b}}$ & $0.01^{\mathrm{a}}$ & $0.29^{d}$ & $0.10^{\mathrm{b}}$ & 0.95 & $0.03^{\mathrm{a}}$ & $0.23^{c}$ & $0.15^{\mathrm{b}}$ & $0.69^{h}$ & $0.17^{\mathrm{bc}}$ & $0.37^{\mathrm{de}}$ & $0.28^{\mathrm{d}}$ \\
\hline rosemary & 0.85 & $0.71^{\mathrm{h}}$ & $0.81^{\mathrm{i}}$ & $0.62^{\mathrm{g}}$ & $0.13^{\mathrm{b}}$ & $0.79^{\mathrm{i}}$ & $0.81^{\mathrm{i}}$ & 0.71 & 1.42 & 0.95 & $0.90^{\mathrm{i}}$ & $0.83^{\mathrm{i}}$ & 1.06 & 0.90 & $0.71^{\mathrm{h}}$ & 0.80 \\
\hline common nettle & $0.28^{\mathrm{d}}$ & $0.11^{\mathrm{b}}$ & $0.62^{\mathrm{g}}$ & $0.43^{\mathrm{e}}$ & $0.56^{\mathrm{fg}}$ & $0.26^{\mathrm{cd}}$ & $0.56^{\mathrm{fg}}$ & $0.48^{\mathrm{f}}$ & $0.73^{\mathrm{h}}$ & $0.39^{\mathrm{e}}$ & $0.90^{\mathrm{i}}$ & $0.56^{\mathrm{fg}}$ & $0.64^{\mathrm{g}}$ & $0.41^{\mathrm{e}}$ & $0.75^{\mathrm{h}}$ & $0.74^{\mathrm{h}}$ \\
\hline clove & $0.09^{\mathrm{b}}$ & $0.00^{\mathrm{a}}$ & $0.23^{c}$ & $0.03^{\mathrm{a}}$ & $0.18^{\mathrm{c}}$ & $0.00^{\mathrm{a}}$ & $0.11^{\mathrm{b}}$ & $0.01^{\mathrm{a}}$ & $0.08^{\mathrm{b}}$ & $0.00^{\mathrm{a}}$ & $0.32^{\mathrm{d}}$ & $0.05^{\mathrm{a}}$ & $0.03^{\mathrm{a}}$ & $0.00^{a}$ & $0.29^{\mathrm{d}}$ & $0.05^{\mathrm{a}}$ \\
\hline lavender & 1.01 & $0.80^{\mathrm{i}}$ & 0.86 & $0.71^{\mathrm{h}}$ & 0.93 & $0.76^{\mathrm{hi}}$ & $0.76^{\mathrm{hi}}$ & $0.85^{\mathrm{i}}$ & 1.49 & $0.84^{\mathrm{i}}$ & $0.90^{\mathrm{i}}$ & $0.90^{\mathrm{i}}$ & $0.75^{\mathrm{h}}$ & $0.72^{\mathrm{h}}$ & $0.67^{\text {gh }}$ & $0.75^{\mathrm{h}}$ \\
\hline chamomile & $0.64^{\mathrm{g}}$ & $0.16^{\mathrm{bc}}$ & $0.56^{\mathrm{fg}}$ & $0.12^{\mathrm{b}}$ & & $0.00^{\mathrm{a}}$ & $0.37^{\mathrm{e}}$ & & 0.99 & & $0.34^{\mathrm{d}}$ & & $0.52^{\mathrm{f}}$ & $0.04^{\mathrm{a}}$ & $0.35^{\mathrm{d}}$ & $0.59^{\mathrm{g}}$ \\
\hline elderberry & 1.24 & $0.79^{\mathrm{i}}$ & $0.66^{\mathrm{gh}}$ & $0.60^{\mathrm{g}}$ & 1.24 & $0.82^{\mathrm{i}}$ & $0.76^{\mathrm{hi}}$ & $0.55^{\mathrm{fg}}$ & 1.40 & $0.91^{\mathrm{i}}$ & $0.76^{\mathrm{hi}}$ & $0.71^{\mathrm{h}}$ & 0.99 & $0.74^{\mathrm{h}}$ & $0.10^{\mathrm{b}}$ & 0.79 \\
\hline plantago & $0.56^{\mathrm{fg}}$ & $0.42^{\mathrm{e}}$ & $0.21^{\mathrm{c}}$ & $0.12^{\mathrm{b}}$ & $0.67^{\mathrm{gh}}$ & $0.39^{\mathrm{e}}$ & $0.30^{\mathrm{d}}$ & $0.20^{c}$ & $0.80^{\mathrm{i}}$ & $0.52^{\mathrm{f}}$ & $0.47^{\text {ef }}$ & $0.22^{c}$ & $0.72^{\mathrm{h}}$ & $0.60^{\mathrm{g}}$ & $0.70^{\mathrm{h}}$ & $0.54^{\mathrm{f}}$ \\
\hline marjoram & 0.85 & $0.77^{\mathrm{hi}}$ & 0.85 & $0.81^{\mathrm{i}}$ & $0.80^{\mathrm{i}}$ & $0.65^{\mathrm{g}}$ & $0.69^{\mathrm{h}}$ & $0.76^{\mathrm{hi}}$ & $0.85^{\mathrm{i}}$ & $0.73^{\mathrm{h}}$ & $0.72^{\mathrm{h}}$ & $0.78^{\mathrm{i}}$ & $0.73^{\mathrm{h}}$ & 0.82 & 0.81 & 0.76 \\
\hline St. John's wort & $0.69^{\mathrm{h}}$ & $0.30^{\mathrm{d}}$ & $0.37^{\mathrm{e}}$ & $0.23^{c}$ & $0.65^{\mathrm{g}}$ & $0.29^{d}$ & $0.35^{\mathrm{d}}$ & $0.20^{c}$ & 0.94 & $0.41^{\mathrm{e}}$ & $0.49^{f}$ & $0.27^{\mathrm{cd}}$ & $0.71^{\mathrm{h}}$ & $0.49^{f}$ & $0.46^{\mathrm{ef}}$ & $0.33^{\mathrm{d}}$ \\
\hline ginger & 0.85 & $0.42^{\mathrm{e}}$ & $0.40^{\mathrm{e}}$ & $0.21^{\mathrm{c}}$ & $0.77^{\mathrm{hi}}$ & $0.33^{\mathrm{d}}$ & $0.36^{\mathrm{de}}$ & $0.10^{\mathrm{b}}$ & $0.84^{\mathrm{i}}$ & $0.53^{f}$ & $0.50^{f}$ & $0.39^{\mathrm{e}}$ & 0.89 & $0.57^{\mathrm{fg}}$ & $0.53^{f}$ & $0.31^{\mathrm{d}}$ \\
\hline negative control & 0.87 & 0.85 & 0.85 & 0.85 & 0.91 & 0.92 & 0.92 & 0.92 & 0.94 & 1.00 & 1.00 & 0.99 & 0.90 & 0.80 & 0.80 & 0.79 \\
\hline
\end{tabular}

Results are expressed as mean values of two incubation experiments ( $t$ (incubation) $=24 \mathrm{~h}$ ). Mean values with different letter in superscript are statistically different $(\mathrm{p}<0.05)$. Values with any letter in superscript have statistically significant antimicrobial effect $(\mathrm{p}<0.05)$. $\mathrm{PE}=$ plant extracts without encapsulation; encapsulation particles: $\mathrm{L}=$ liposomes, $\mathrm{A}=$ alginate, $\mathrm{CH}=$ chitosan

clove, coneflower, sage or thyme also had the most pronounced antimicrobial activity. However, a very good antibacterial activity was detected in some herbs with lower antioxidant activity (for example liquorice, sea buckthorn, common nettle, wormwood, pot marigold and chamomile). On the other hand, in marjoram extract, with high antioxidant activity (Table 1), only minimum antimicrobial effect was found (Table 9). Some non-phenolic constituents of the extract also have the capability to act as antimicrobial agents (14).

Furthermore, antimicrobial activities of extracts encapsulated in different materials (liposome, alginate and chitosan particles) were compared. High antimicrobial effect against all tested strains, mainly Gram-positive, was observed in extracts encapsulated in chitosan particles and then in liposome. Except rosemary, all tested extracts exhibited a statistically significant increase of antimicrobial activity against all tested strains after encapsulation into liposome particles (Table 9). The best antimicrobial activity (predominantly against Gram-positive bacteria) was detected in liposomes containing extracts of clove and lysozyme. These particles showed a $100 \%$ antimicrobial protection against all tested strains throughout $24 \mathrm{~h}$. A very high antimicrobial effect against all strains was measured in liposome containing sage, sea buckthorn or chamomile extract. Liposomes containing wormwood and coneflower extracts had almost $100 \%$ inhibitory effect against $S$. marcescens. Liposomes contain- ing pot marigold and liquorice extracts also had high antimicrobial activity (Table 9).

Chitosan particles exhibited statistically significant antimicrobial activity against all tested strains, particularly particles with encapsulated extracts of clove, sea buckthorn, sage or liquorice. High antimicrobial effect against Gram-negative strains was observed in chitosan particles, comparable with liposomes. In Gram-negative strains combination of test strains and type of encapsulated extract was more important than in Gram-positive strains. Generally, Gram-negative strains were sensitive mainly against particles containing wormwood and clove extracts. S. marcescens was highly sensitive to sage extract, while in E. coli antimicrobial effect was confirmed also using the extracts of liquorice and sea buckthorn (Table 9). In conclusion, encapsulation of plant extracts into liposomes and chitosan particles led in most cases to an increase and prolongation of antimicrobial effect of the extracts. This effect could be caused by increased stability of active substances entrapped in polymer capsule.

It is interesting that chitosan particles had the highest inhibitory effect, but the lowest encapsulation efficiency. These results (Table 9) confirm the findings of another study (19) about the possible application of antimicrobial activity of chitosan. Chitosan due to its polycationic nature can interact with negatively charged microbial cell walls and plasma membranes, resulting in decreased osmotic stability, membrane disruption and eventual leak- 
age of intracellular elements. In addition, chitosan is able to inhibit mRNA and protein synthesis by binding to microbial DNA. Nanoscale chitosan that has a higher surface-to-volume ratio, resulting in higher surface charge density, leads to increased affinity towards bacteria and fungi and greater antimicrobial activity. Therefore, it is suitable for encapsulation of antimicrobial ingredients (19).

By testing the antimicrobial activity of lysozyme, high effect against all tested strains was reported (Fig. 4). However, the inhibitory effect against E. coli was very slight and at lower concentrations of lysozyme, no effect was observed. In particular, the highest effect was observed against Gram-positive strains (B. subtilis and $M$. luteus). Interestingly, relatively high antimicrobial effect was achieved against Gram-negative S. marcescens. The minimum inhibitory concentration of lysozyme was determined to be more than $500 \mu \mathrm{g} / \mathrm{mL}$ against B. subtilis, $1000 \mu \mathrm{g} / \mathrm{mL}$ against $M$. luteus and more than $1000 \mu \mathrm{g} / \mathrm{mL}$ against Gram-negative strains (Fig. 4).

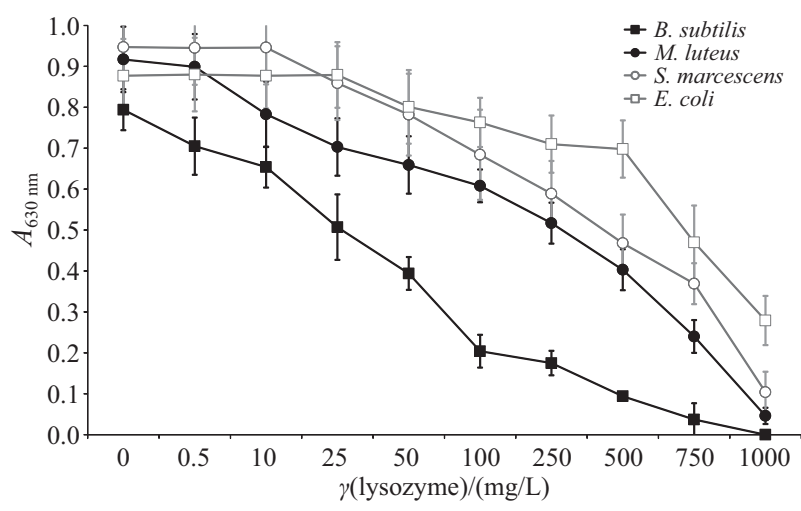

Fig. 4. Determination of antimicrobial activity of lysozyme using broth dilution assay $(t$ (incubation $)=24 \mathrm{~h}$ )

Liposomes with co-encapsulated lysozyme (at concentrations of 1 and $0.5 \mathrm{mg} / \mathrm{mL}$ ) and selected plant extracts were subjected to testing the antimicrobial activity as well (Fig. 5). High antimicrobial activity, particularly against Gram-positive strains was detected in all particles. In liposome particles containing a mixture of plant extracts and lysozyme, a statistically significant increase of antimicrobial effect compared to liposomes containing plant extracts only was observed (Fig. 5, Table 9). The particles with mixed antimicrobial substances exhibited significantly higher antimicrobial activity against all tested strains (Fig. 5). Higher concentration of lysozyme led to increased antimicrobial effect. From the obtained results it is clear that some plant extracts, such as sage or thyme, are able to enhance lysozyme effect mainly against Gram-negative strains. These preparations can be used as antimicrobial agents with broader antimicrobial activity applicable in food and cosmetics industries.

The antimicrobial activity of particles containing lysozyme and plant extract was studied after 7 and 30 days of storage (Table 10). The results showed that after the application of model conditions, partial loss of antimicrobial activity was observed. Antimicrobial tests confirmed the assumption that free lysozyme in different media over
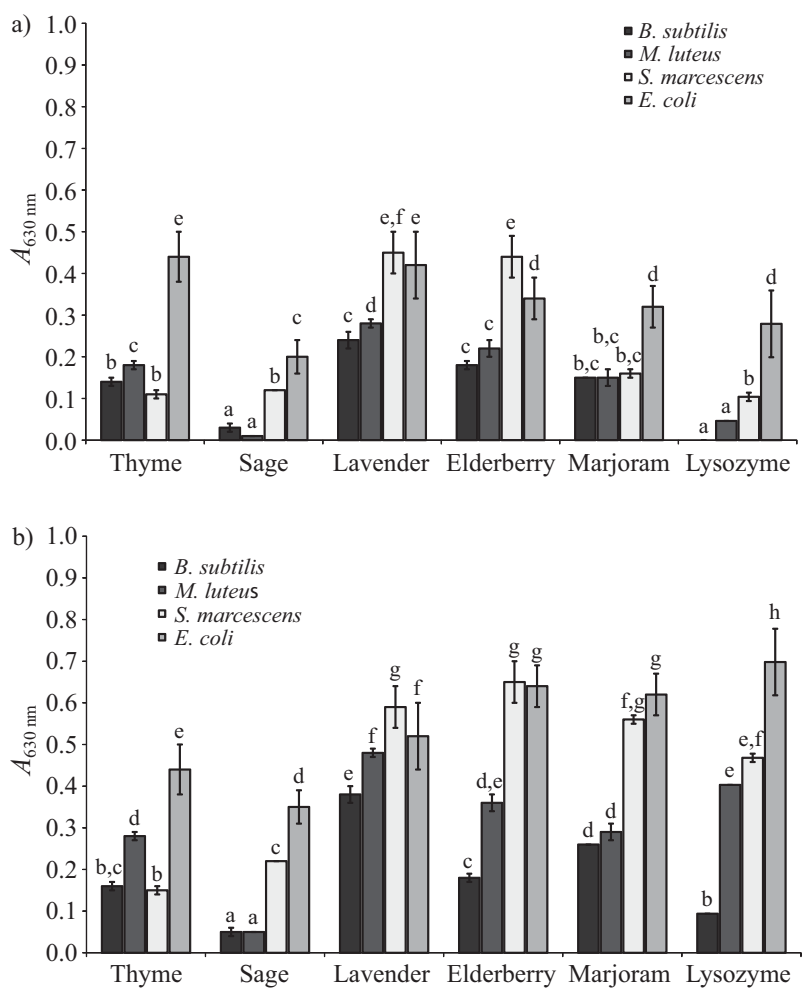

Fig. 5. Determination of antimicrobial activity of particles with selected co-encapsulated herb and spice extracts and lysozyme: a) $\gamma$ (lysozyme) $=1 \mathrm{mg} / \mathrm{mL}$, and b) $\gamma($ lysozyme $)=0.5 \mathrm{mg} / \mathrm{mL}$, determined turbidimetrically $\left(A_{630 \mathrm{~nm}}\right)$ using broth dilution assay $(t$ (incubation $)=24 \mathrm{~h})$

time degrades or denatures and loses more than $50 \%$ of its activity. The obtained results therefore confirm that free lysozyme is relatively unstable and its encapsulation in combination with plant extract may significantly affect its stability. The antimicrobial activity of the prepared liposomes with antimicrobial substances was maintained for a relatively long time. B. subtilis was sensitive to particles containing lysozyme, thyme and sage stored for more than one month, while the antimicrobial activity of these complex extracts against other tested strains decreased to about $50 \%$ of the original activity. Therefore, particles with co-encapsulated herbs and lysozyme are more active against different types of bacteria, and are more stable and more effective during long-term storage.

Relatively good stability of particles that have low resistance under certain conditions is a suitable basis for the development of preparations with a targeted transport of antimicrobial substances and their controlled release. An important factor for the maintenance of antimicrobial activity is the ability to release antimicrobial agents in a sufficiently short time and at the required minimum inhibitory concentration. All of the tested particles with coencapsulated herb extracts and lysozyme had very good inhibitory effect against all tested strains. Based on the results, it can be concluded that the most appropriate environment for storage of prepared particles is an aqueous medium. The prepared particles are suitable for application in various food industries and also in the form of water-based gels, especially for application in cosmeceuticals (18). 
Table 10. Stability of antimicrobial activity of liposomes with co-encapsulated lysozyme and plant extracts during long-term storage compared with non-encapsulated lysozyme $(\gamma=1 \mathrm{mg} / \mathrm{mL})$

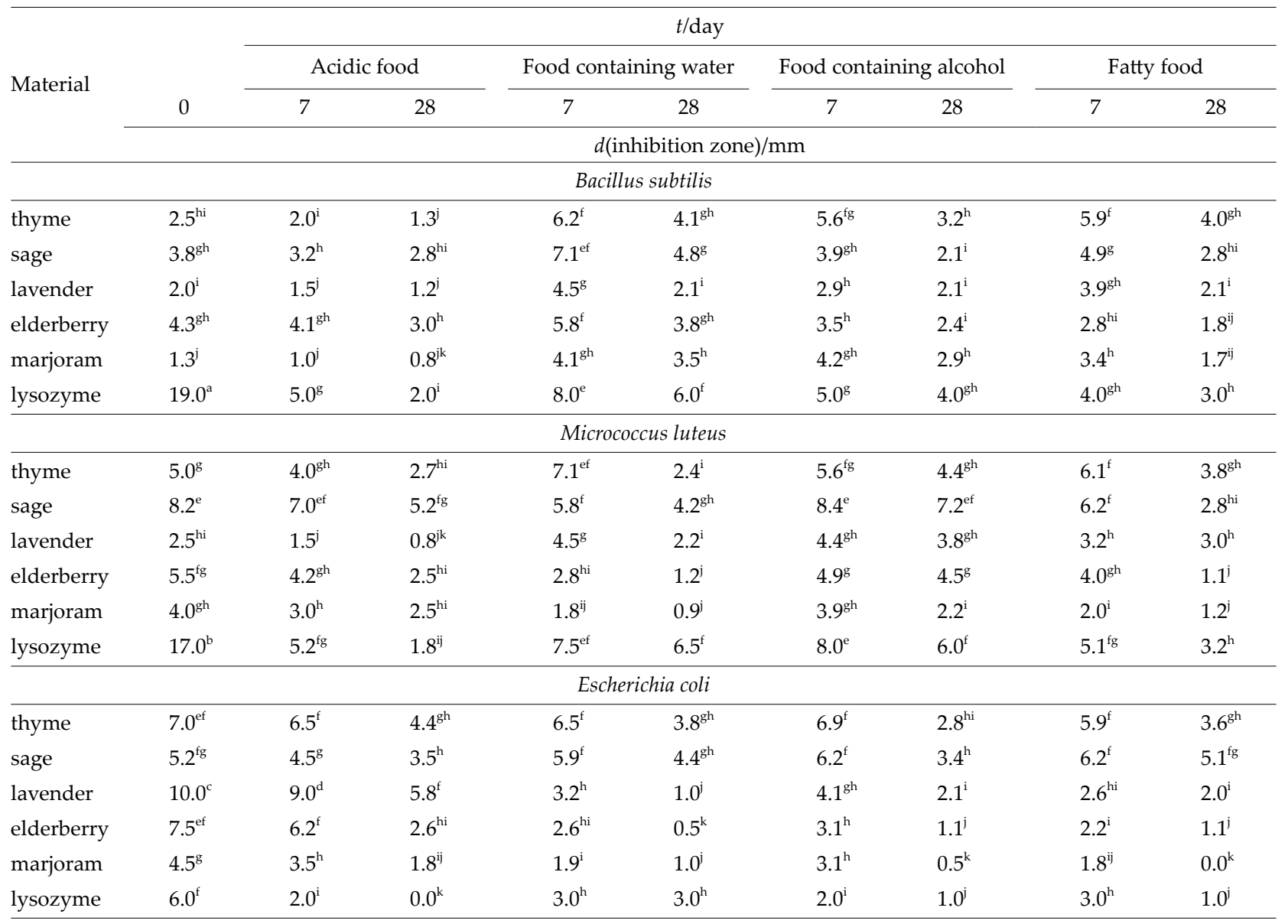

Antimicrobial activity was measured by well diffusion assay. Inhibition zones represent the average values of two measurements. Mean values with different letters in superscript are statistically different $(p<0.05)$

\section{Conclusions}

In this study the antimicrobial activities of lysozyme, nisin and extracts of various spices and herbs before and after encapsulation were tested. Antimicrobial components were packaged into liposome and polysaccharide particles (alginate, chitosan or starch). Encapsulation of phenolic components was successful with all types of extracts. Encapsulation efficiency of herbal extracts depended on the particle material and extract composition, while encapsulation efficiency of lysozyme was relatively good in all particles. All prepared particles exhibited very good colloid stability (zeta potential). Antimicrobial tests (agar well diffusion method and broth dilution assay) were done using two Gram-negative and two Gram-positive bacterial strains. This study demonstrated that some extracts of the tested herbs and spices have a potential for a very good antimicrobial activity against both Gram-positive and Gram-negative bacterial strains. Lysozyme and nisin exhibited high antimicrobial effect, mainly against the tested Gram-positive bacteria. Chitosan particles with plant extracts also exhibited very high inhibitory effect. This could be useful to achieve their combined effect; unfortu- nately, chitosan particles were less stable than those of liposomes. Long-term stability and the mass fraction of released components in food and models of physiological conditions were also monitored. Prepared particles could be stored predominantly in an aqueous medium, where they are stable for more than one month and retain their antimicrobial activity. The particles containing encapsulated antimicrobial herb and spice extracts and lysozyme can be used for various food applications. They can also be used as antimicrobial hydrogel formulation containing antimicrobial nanoparticles with controlled release. Antibacterial effect of the gel together with the antioxidant activity of herb and spice extracts could be a very promising tool for disinfection or wound healing therapy. Other potential applications of the prepared particles are in food preservation and in pharmaceutical antimicrobial products.

\section{Acknowledgement}

This work was supported by the project 'Materials Research Centre - Sustainability and Development' No. LO1211 of the Ministry of Education, Youth and Sport of the Czech Republic. 


\section{References}

1. Jungmin $\mathrm{OH}$, Heonjoo J, Ah Reum C, Sung-Jin K, Jaejoon $\mathrm{H}$. Antioxidant and antimicrobial activities of various leafy herbal teas. Food Control. 2013;31:403-9. http://dx.doi.org/10.1016/j.foodcont.2012.10.021

2. Chirinos R, Pedreschi R, Rogez H, Larondelle Y, Campos D. Phenolic compound contents and antioxidant activity in plants with nutritional and/or medicinal properties from the Peruvian Andean region. Ind Crop Prod. 2013;47:145-52. http://dx.doi.org/10.1016/j.indcrop.2013.02.025

3. Ferrazano GF, Amato I, Ingenito A, Zarrelli A, Pinto G, Pollio A. Plant polyphenols and their anti-cariogenic properties: a review. Molecules. 2011;16:1486-507. http://dx.doi.org/10.3390/molecules16021486

4. Daglia M. Polyphenols as antimicrobial agents. Curr Opin Biotech. 2012;23:174-81. http://dx.doi.org/10.1016/j.copbio.2011.08.007

5. Cushine TPT, Lamb AJ. Antimicrobial activity of flavonoids. Int J Antimicrob Agents. 2005;26:343-56. http://dx.doi.org/10.1016/j.ijantimicag.2005.09.002

6. Neves MA, Hasemi J, Prentice C. Development of novel bioactive delivery systems by micro/nanotechnology. Curr Opin Food Sci. 2015;1:7-12. http://dx.doi.org/10.1016/j.cofs.2014.09.002

7. Tenover FC, Swenson JM, O'Hara CM, Stocker SA. Ability of commercial and reference antimicrobial susceptibility testing methods to detect vancomycin resistance in enterococci. J Clin Microb. 1995;33:1524-7.

8. Sharma A, Kumar Arya D, Dua M, Chhatwal GS, Johri AK. Nano-technology for targeted drug delivery to combat antibiotic resistance. Expert Opin Drug Deliver. 2012;9:1325-32. http://dx.doi.org/10.1517/17425247.2012.717927

9. Munin A, Edwards-Lévy F. Encapsulation of natural polyphenolic compounds; a review. Pharmaceutics. 2011;3:793829. http://dx.doi.org/10.3390/pharmaceutics3040793

10. Weerakkody N, Caffin SN, Turner MS, Dykes GA. In vitro antimicrobial activity of less-utilized spice and herb extracts against selected food-borne bacteria. Food Control. 2010;21: 1408-14. http://dx.doi.org/10.1016/j.foodcont.2010.04.014

11. de Andrade EF, de Souza Leone R, Ellendersen LN, Masson ML. Phenolic profile and antioxidant activity of extracts of leaves and flowers of yacon (Smallanthus sonchifolius). Ind Crop Prod. 2014;62:499-506. http://dx.doi.org/10.1016/j.indcrop.2014.09.025

12. Xue J, Davidson PM, Zhong Q. Antimicrobial activity of thyme oil co-nanoemulsified with sodium caseinate and leci- thin. Int J Food Microbiol. 2015;210:1-8. http://dx.doi.org/10.1016/j.ijfoodmicro.2015.06.003

13. Zhai $Y$, Zhai G. Advances in lipid-based colloid systems as drug carrier for topic delivery. J Control Release. 2014;193:909. http://dx.doi.org/10.1016/j.jconrel.2014.05.054

14. Zhang L, Pornpattananangkul D, Hu CHJ, Huang CM. Development of nanoparticles for antimicrobial drug delivery. Curr Med Chem. 2010;17:585-94. http://dx.doi.org/10.2174/092986710790416290

15. Wu L, Zhang J, Watanabe W. Physical and chemical stability of drug nanoparticles. Adv Drug Delivery Rev. 2011;63:45669. http://dx.doi.org/10.1016/j.addr.2011.02.001

16. Basnet P, Skalko-Basnet N. Nanodelivery systems for improved topical antimicrobial therapy. Curr Pharm Des. 2013; 19:7237-43. http://dx.doi.org/10.2174/138161281941131219124856

17. Akbarzadeh A, Rezaei-Sadabady R, Davaran S, Joo SW, Zarghami N, Hanifehpour Y, et al. Liposome: classification, preparation, and applications. Nano Res Lett. 2013;8:102. http://dx.doi.org/10.1186/1556-276X-8-102

18. Rahimpour $Y$, Hamishehkar H. Liposomes in cosmeceutics. Expert Opin Drug Deliv. 2012;9:443-55. http://dx.doi.org/10.1517/17425247.2012.666968

19. Denkbaş EB, Odabaşi M. Chitosan microspheres and sponges: preparation and characterization. J Appl Polym Sci. 2000; 76:1637-43.

http://dx.doi.org/10.1002/(SICI)1097-4628(20000613)76:11<16 37::AID-APP4>3.0.CO;2-Q

20. Chin SF, Pang SC, Tay SH. Size controlled synthesis of starch nanoparticles by a simple nanoprecipitation method. Carbohydr Polym. 2011;86:1817-9.

http://dx.doi.org/10.1016/j.carbpol.2011.07.012

21. Re R, Pellegrini N, Proteggente A, Pannala A, Yang M, RiceEvans C. Antioxidant activity applying an improved ABTS radical cation decolorization assay. Free Radic Biol Med. 1999;26:1231-7. http://dx.doi.org/10.1016/S0891-5849(98)00315-3

22. Singleton VL, Rossi JA. Colorimetry of total phenolics with phosphomolybdic-phosphotungstic acid reagents. Am J Enol Vitic. 1965;16:144-58.

23. Chang CC, Yang MH, Wen HM, Chern JC. Estimation of total flavonoid content in propolis by two complementary colorimetric methods. J Food Drug Anal. 2002;10:178-82.

24. Wiegand I, Hilpert K, Hancock REW. Agar and broth dilution methods to determine the minimal inhibitory concentration (MIC) of antimicrobial substances. Nature Protocols. 2008;3:163-75. http://dx.doi.org/10.1038/nprot.2007.521 